\title{
UN PROBLEMA DE HISTORIOGRAFÍA Y CRONOLOGÍA: LA FECHA DE NACIMIENTO DEL CARDENAL JIMÉNEZ DE CISNEROS
}

\author{
POR \\ FRANCISCO VÁZQUEZ MARTíNEZ \\ Investigador. Biblioteca Valenciana \\ vzquezc@gmail.com
}

\section{RESUMEN}

En este artículo se cuestiona la fecha tradicional del nacimiento del cardenal Jiménez de Cisneros, mediante el examen de la historiografía tanto antigua como moderna, y de la cronología de sus parientes y contemporáneos. Como resultado de ella se sugiere una fecha más probable de dicho nacimiento y se da una nueva cronología de los primeros años de su vida.

PALABRAS CLAVE: Jiménez de Cisneros, Cardenal, fecha de nacimiento, historiografía, cronología.

\section{A PROBLEM OF HISTORIOGRAPHY AND CHRONOLOGY: THE BIRTH'S DATE OF CARDINAL JIMENEZ DE CISNEROS}

\section{ABSTRACT}

In this article the traditional birth's date of Cardinal Jimenez de Cisneros is questioned, by means of an inquiry into the historiography, both ancient and modern, and the chronology of his family and contemporaries. As a result, a most likely date for his birth is suggested, and a new chronology for the fist years of his life is given.

KEY WORDS: Jimenez de Cisneros, Cardinal, birth's date, historiography, chronology

Recibido/Received 26-05-2013

Aceptado/Accepted 24-02-2016

\section{LA BIOGRAFÍA TRADICIONAL DEL CARDENAL CISNEROS}

Antes de abordar la cuestión que proponemos, vamos a resumir la versión tradicional de la biografía de los primeros años del cardenal Cisneros que ha llegado, con escasas variantes, hasta nuestros días. Esa biografía tradicional, que luego completaremos con un cotejo de las variantes que aportan las distintas fuentes antiguas, podríamos resumirla con los datos que proporcionan dos autores, uno antiguo y otro moderno, con escasas diferencias. Nos referimos a Quintanilla, ${ }^{1}$ que es el último de sus biógrafos clásicos, pero el primero que da una cronología congruente de la vida del cardenal, en lo que se refiere a sus primeros años, y a García Oro, que en su artículo biográfico del Diccionario de Historia Eclesiástica de España, ${ }^{2}$

1 Pedro de Quintanilla y Mendoza, autor de Archetypo de virtudes, espejo de prelados, el venerable padre y siervo de Dios Fray Francisco Ximénez de Cisneros (1653).

2 García Oro, J. 1972. "Jiménez de Cisneros, Francisco" en Q. Aldea (Dir.). Diccionario de Historia Eclesiástica de España II: 1238-39. Madrid. CSIC. resume esos mismos datos con alguna variante derivada de los descubrimientos producidos en el siglo $x x$, pero manteniendo todavía en sustancia la versión tradicional formulada en siglos anteriores.

Es Quintanilla el primero que afirma que nació Jiménez de Cisneros en 1436, y según él marchó a estudiar a Salamanca a los 14 años. Regresó de allí siendo de 22 años, marchando a Roma en 1459, y allí residió ejerciendo de abogado hasta que en 1465 regresa a su patria por muerte de su padre. Trae consigo una bula expectativa que utiliza al producirse una vacante que le interesa, el arciprestazgo de Uceda, a la que opta, pero por causa de ello incurre en desgracia con su arzobispo, el temible Alonso Carrillo de Acuña, que le hace encarcelar; pasa más de seis años en diversas prisiones, y sólo en 1480 , liberado ya, se traslada a Sigüenza donde el cardenal Mendoza le nombra capellán mayor de la catedral. Daremos más adelante los detalles de este periodo, con sus correspondientes citas, pues ahora tratamos tan sólo de resumir una biografía que dejamos en este punto, al no existir respecto de los años sucesivos discrepancia cronológica seria. 
Comparemos esta biografía con la que, tres siglos largos después, da García Oro en el mencionado Diccionario de Historia Eclesiástica de España:

Francisco Jiménez de Cisneros nació en Torrelaguna (Madrid) el año 1436, de padres hidalgos (Alfonso Jiménez y María de la Torre), procedentes de la villa de Cisneros (provincia de Palencia). Destinado a la carrera eclesiástica, realiza sus primeros estudios en Roa, al lado de un tío clérigo, y en Alcalá de Henares, en el Estudio Viejo anejo al convento de los franciscanos. Hace estudios universitarios en Salamanca, culminando con el grado de bachiller en Derecho. Con propósito de entrenarse en la administración eclesiástica y encontrar mejor fortuna, se dirige a Roma, de donde regresa pronto a España por imperativos familiares. El 22 de enero de 1471 es nombrado por Paulo II arcipreste de Uceda, con sorpresa y desagrado del arzobispo de Toledo, D. Alfonso Carrillo. A esta decisión llegaba el pontífice al ser informado por el mismo Cisneros de una grave infracción de la jurisdicción eclesiástica hecha por su antecesor Pedro García de Guaza. Cisneros defendió tenazmente su derecho al arciprestazgo contra la oposición del arzobispo, siendo, por este motivo, sancionado con largos años de cárcel por el turbulento prelado. Termina su dura prisión logrando, al parecer, su intento. Pero, ante el temor de otras represalias, decide, con la protección del cardenal González de Mendoza, pasar al obispado de Sigüenza en donde es nombrado capellán mayor en 1480.

Hasta aquí una versión casi literal, aunque resumida, del citado artículo biográfico de García Oro, que no precisamos prolongar porque, como hemos dicho, la cronología posterior de Cisneros está bien establecida.

Vemos que, sustancialmente, apenas hay diferencias entre ambas versiones, lo que de alguna manera consolida la biografía del cardenal, indiscutida durante tantos siglos. No obstante, una mayor aproximación a la versión de García Oro nos permite advertir algunas diferencias que, aunque pequeñas, son ya significativas. En primer lugar, ha desaparecido la clara cronología de sus primeros años que daba Quintanilla. Sí, estudió en Salamanca y marchó a Roma, pero su regreso (pronto) desmiente implícitamente la estancia de seis años que daba Quintanilla. También la muerte de su padre aparece ahora sólo aludida mediante una expresión más vaga (imperativos familiares). Pero la principal diferencia radica en la bula de nombramiento como arcipreste de Uceda. Como luego veremos, para entonces dicha bula se había publicado, y la versión que de ella daban las biografías tradicionales del cardenal era insostenible. Todo lo demás, sin embargo, se mantiene, incluidos los largos años de prisión y su traslado a Sigüenza en 1480 . Posteriores publicaciones alterarán esta versión biográfica de García Oro de manera que hay que calificar de sustancial, pero esto lo veremos más adelante. Porque, en gran medida, y sobre todo para el público menos experto, ésta es la versión todavía vigente de la biografía de Cisneros.

$Y$ en ella lo que resulta llamativo es una cierta indefinición de la actividad y hasta situación de Cisneros en un largo periodo que va desde 1459, cuando presuntamente sale de Salamanca, a 1471, cuando es nombrado arcipreste de Uceda. Indefinición que en vez de disminuir, se agudiza en la versión de García Oro. En efecto, la biografía de Quintanilla empleaba la mitad de ese periodo en una estancia en Roma que en García Oro parece recortarse cuando se afirma que regresó pronto. Por cierto que tampoco dice cuándo fuera, pero eso es irrelevante en cuanto a la indefinición del lapso global de tiempo en que no sabemos qué fue de Cisneros.

Esta insuficiencia de la biografía tradicional de Cisneros es la que ha motivado este trabajo de investigación, partiendo de la hipótesis de que un retraso de su fecha de nacimiento en un promedio de doce (o, para dar un cierto margen, entre diez y quince) años daría más coherencia a la biografía. Los datos recabados parecen mostrar que no sólo le da una mayor coherencia, sino que se acomoda más a hechos y datos contemporáneos que sus biógrafos han afirmado contradictoriamente, que no han tenido en cuenta, o han omitido, basados en una certeza previa (la de una fecha de nacimiento no documentada) que se ha convertido para ellos casi en una petición de principio.

A este fin nos parece preciso un repaso de sus principales biografías, tanto tradicionales como modernas, cotejando luego los datos de las mismas con lo que sabemos de la cronología de Cisneros, de sus parientes y contemporáneos. Como resultado de ello, trataremos de reconstruir una cronología más probable de los primeros años del cardenal.

\section{HISTORIOGRAFÍA CLÁSICA}

Las biografías clásicas del cardenal Cisneros son cuatro, de las que las posteriores han copiado con escasas variantes. Por orden cronológico de composición son:

El Memorial de la vida de fray Francisco Jiménez de Cisneros de Juan de Vallejo. Éste fue paje y luego camarero del entonces sólo arzobispo de Toledo. A los efectos de este artículo, no importa demasiado ni la fecha de su redacción (que se sitúa en torno a 1530), ni la fecha en que Vallejo entró al servicio de Cisneros, que no debió ser posterior a 1498, aunque algunos detalles (y la afirmación de Quintanilla) retrotraen su primer contacto personal con el arzobispo a 1495. Y aunque su autoría descansa en la palabra de Gómez de Castro (pues el manuscrito no menciona al autor, ni éste, cuando se nombra, lo hace en primera persona) nadie la ha puesto seriamente en tela de juicio.

Debe subrayarse que, entre todos sus biógrafos, fue Vallejo el único que conoció personalmente y trató al cardenal, que pudo oír de su boca o de la de personas de su entorno detalles biográficos, y que, a partir de su nombramiento como arzobispo de Toledo, fue testigo personal de muchos de los hechos de su biografía. Pero ese carácter de testigo presencial no lo tiene para los años anteriores, que son precisamente los que ahora analizamos, y su biografía se interrumpe en el año 1507, y sólo por alguna alusión se nos dan noticias posteriores.

Esto, unido al descuido de los autores antiguos por la cronología, explica que Vallejo no mencione fecha de nacimiento del cardenal, y al no llegar a la fecha de su muerte en su Memorial, tampoco hay en él referencia alguna a la edad que tenía al morir. Aun así, su mención de los hechos relativos a los primeros años de la vida del cardenal tiene gran valor (pero no fehaciente) y algunas fechas que proporciona de años posteriores resultan útiles para 
establecer la cronología de Cisneros, como más adelante veremos.

Señalaremos a continuación los datos que proporciona Vallejo respecto de los primeros años del cardenal, subrayando aquellos datos que difieren de la biografía que hemos resumido al inicio.

Da Vallejo el nombre de los padres del cardenal, ${ }^{3}$ y detalla el de los hermanos, asignando el carácter de primogénito a Gonzalo, el futuro cardenal, y dando por segundo a Juan y por tercero a Bernardino. Menciona, ${ }^{4}$ además, su envío a Roa ( $a$ un tío suyo) y da a continuación una variante respecto de su educación posterior que sitúa en Cuéllar ( $a$ enseñar gramática) en vez de en Alcalá. De sus estudios en Salamanca apenas señala que se hizo grand letrado y tomó grado de bachiller en Decretos. ${ }^{5}$

Relata a continuación, ${ }^{6}$ sin solución de continuidad, que el arzobispo Alonso Carrillo le enbió a llamar y lo rescibió en su serviçio y le...dio cargo que entendiese en aquella governaçión de aquellas villas de Talamanca, Uzeda y Tordelaguna y su tierra.

La vacante del arciprestazgo de Uceda que se produjo en este tiempo, diceVallejo que la ocupó por çierta bulla expetativa que tenía. ${ }^{7}$ La disputa que ello ocasionó con el arzobispo hizo que éste le mandara prender y estar en la fortaleza de Uzeda muchos días.

Suelto que fue, prosigue Vallejo, ${ }^{8}$ se partió para la corte de Roma a litigar su arçiprestazgo y luego se bolvió en España y ovo la capellanía mayor de la santa yglesia de Sigüença.

No hay, como se puede ver en lo relatado, ni una sola fecha y sí una absoluta vaguedad temporal representada con expresiones como "en este tiempo", "muchos días", etc...

Pero es significativo en esta secuencia de hechos que Vallejo recoja el cargo que desempeñó el bachiller Ximénez de Cisneros de gobernador (eclesiástico) de Uceda, obviado por biógrafos posteriores, y que sitúe su viaje a Roma con posterioridad a la concesión del arciprestazgo de Uceda.

Respecto a la duración de la prisión, la expresión muchos días no significa que fuera corta, aunque esto es lo que indica si se toma literalmente. Alguna mención temporal más, que nos será útil, hay en la obra de Vallejo, pero la citaremos en el lugar oportuno.

Ahora bien, si ésta fue la primera biografía de Cisneros en escribirse, fue la última de las clásicas en editarse. El manuscrito de Vallejo, que fue conocido y utilizado por Gómez de Castro para redactar su biografía, permaneció inédito durante casi cuatro siglos, hasta ser editado por Antonio de la Torre y del Cerro en 1913.

La siguiente biografía de Cisneros, en realidad la primera que se publicó, fue la obra de Alvar Gómez de Castro, De rebus gestis a Francisco Ximenio Cisnerio. La escribió éste

3 Vallejo, J. 1913. Memorial de la vida de fray Francisco Jiménez de Cisneros: 2. Torre, A. de la (ed.) Madrid. Imprenta Bailly-Bailliere.

4 Idem.

5 Idem.

6 Ibidem, 2-3.

7 Ibidem, 3.

8 Idem. en latín y a requerimiento del Colegio de S. Ildefonso de Alcalá, donde era catedrático. Como hemos dicho, utilizó el autor el manuscrito de Vallejo, y en realidad, continuó el trabajo iniciado por Juan de Vergara, que murió antes de poder completarlo. Reeditada varias veces, traducida al castellano, ${ }^{9}$ y muy completa y prestigiada, la obra de Gómez de Castro es probablemente la mejor biografía de Cisneros y goza del privilegio de la cercanía con las fuentes, incluso orales, de la vida del arzobispo. Pese a ello, es notorio que el autor no fue testigo presencial de los hechos que narra, si bien contó con documentos y manuscritos conservados en el Colegio de S. Ildefonso, que es dudoso hayan llegado intactos a nuestra época.

Es Gómez de Castro el primero que menciona (indirectamente) la fecha aproximada de nacimiento, ${ }^{10}$ al decir la edad que éste tenía al morir: etatis verò circiter octogessimo. Según esto, habiendo muerto Cisneros a fines de 1517 , lo que se deduce es que nació en torno a 1437. Pero esto no se dice de manera explícita, sino que ha de deducirlo (con una simple resta, es verdad) el lector. Señalemos ahora las características de esta biografía, ${ }^{11}$ que se inicia con una breve mención de la ascendencia paterna del cardenal, que, a los efectos que nos interesan, sólo recogeremos a partir de su abuelo, llamado Toribio, quien tuvo tres hijos, García, Álvaro y Alfonso (según el orden que da Gómez de Castro), y se detiene un momento en la posteridad del primogénito, ${ }^{12}$ García, cuyo hijo homónimo fue abad benedictino de Montserrat, y luego habla de María, que nació antes (qui maior natu fuit) y de la hija de ésta, Juana, que se casaría luego con García de Villarroel que acompañó al cardenal en su expedición a Orán.

Narra luego la separación de los otros dos hermanos que abandonaron el solar familiar, a consecuencia del duro carácter de su hermano mayor. ${ }^{13}$ Si Álvaro no tuvo descendientes (nullos hic liberos procreasse), el tercer hermano, Alfonso, instalado en Torrelaguna y casado con una María (de la que no se menciona apellido), tuvo tres hijos: Francisco, que fue el mayor (maiorem natu) Juan y Bernardino. Menciona Gómez de Castro el nombre de bautismo dado al futuro cardenal (Gonzalo), opinando que se le daría en memoria de un antepasado suyo (Gonzalo Ximénez el Bueno) del que habló al comienzo de su obra. ${ }^{14}$

A continuación, ${ }^{15}$ pone en cuestión la versión de Vallejo según la cual Francisco habría estudiado en Roa con su tío, negando que éste fuera sacerdote, y en cambio afirma que fue enviado a Alcalá (ad grammaticae preceptores Complutu miserunt), tras lo cual marchó el futuro cardenal a Salamanca. Interesa subrayar que según el autor, ${ }^{16}$

\footnotetext{
9 Por José Oroz Reta (De las hazañas de Francisco Jiménez de Cisneros) en 1981.

10 Gómez de Castro, A. 1569. De rebus gestis a Francisco Ximenio Cisnerio, archiepiscopo Toletano, libri octo.: f. 215 v. Compluti, apud Andream de Angulo.

11 Ibídem, ff.1-2.

12 Ibídem, f. 1 v.

13 Ídem: Alvarus \& Alphonsus, duro Garsiae fratri ingenio cedentes, Campensi regione relicta, in transmontana sese contulerunt.

14 Ibídem., f. 2 r.

15 Ídem.

16 Ídem.
} 
allí (además de sus estudios de derecho) estudió filosofía y teología con el maestro Roa (non gravatus etiam in publicis philosophiae, theologiaeque; scholis operam dare magistro Roensi celeberrimo tunc harum doctrinarum professori). Acabados sus estudios de derecho, regresó a la casa paterna donde ejerció el derecho con la ayuda de su padre (qui forenses causas procurabat). Marchó a Roma a continuación, y se nos cuenta la que probablemente es la primera versión de sus vicisitudes durante el viaje, ${ }^{17}$ luego repetida en las biografías posteriores, pero que aquí omitimos, por carecer de relevancia para el asunto que tratamos. En Roma ejerció el derecho hasta que se le anunció la muerte de su padre y regresó a su patria. Es entonces cuando solicitó la así llamada bula expectativa (litteras vulgo expectativas vocant) obteniendo así el arciprestazgo de Uceda, que quedó vacante. Viene luego el relato de su detención y prisión, ${ }^{18}$ en Uceda y Santorcaz por el arzobispo Carrillo, para cuya duración no da un dato más preciso que Vallejo (complures dies ibi detentus). Liberado, pasó a ser capellán mayor de Sigüenza, con lo que concluye la parte de biografía que nos interesa analizar. Señalemos, sin embargo, que Gómez de Castro menciona expresamente la versión dada por Vallejo sobre su cargo anterior al de arcipreste y su viaje posterior a Roma, que califica de inverosímil (verissimile non est). ${ }^{19}$

Como se ve, hay en ella una ausencia total de cronología, y, salvo las variantes señaladas, apenas se diferencia de la anterior, aunque hay que subrayar el mayor detalle en la descripción de sus estudios en Salamanca. Igualmente hay una noticia algo más detallada de la boda de su hermano Juan, de la que ahora no referiremos sino el dato, que se precisa expresamente, ${ }^{20}$ de que era el segundo nacido después de él (de uxore loanni Ximenio fratri, qui secundus natu fuerat).

La siguiente biografía es el Compendio de la vida y hazañas del cardenal...Ximénez de Cisneros, de Eugenio de Robles, editada en 1604. Era Robles capellán de la capilla mozárabe de Toledo, y considera su biografía como una introducción para tratar del rito mozárabe, asunto éste extraño a nuestro propósito. Cita la biografía de Gómez de Castro, al que pretende seguir (a quien seguiré, afirma). ${ }^{21}$ Pero desde sus primeras líneas introduce algunas novedades, ampliando las noticias sobre la familia del cardenal, admirado -dice- de la poca mención que hacen de sus padres los que escribieron de su vida, ${ }^{22}$ considerando muy poco lo que de ellos trae Gómez de Castro. Y en efecto, corrige a éste sobre el nombre de la madre del cardenal a la que llama Marina Ximénez de la Torre, y no María. ${ }^{23}$ Del origen de su matrimonio con ésta da una versión más amplia y algo distinta. ${ }^{24}$ Según ésta,

17 Ídem.

18 Ibídem., I, ff.2-3.

19 Ibídem., I, f. 3.

20 Ibídem, f. 25.

21 Robles, E. 1604. Compendio de la vida y hazañas del Cardenal don Fray Francisco Ximénez de Cisneros; y del Oficio y Missa Muzárabe: 2 Valladolid.

22 Ibídem, 3.

23 Ibídem, 4.

24 Ibídem, 5. por desabrimientos y disgustos que tuvo con su hermano mayor (que es el que tenía la casa y mayorazgo de su padre) marchó a estudiar a Salamanca y yendo en las vacaciones a Tordelaguna, conoció allí a Marina, con la que luego se casó. Repite el orden de los hermanos de su padre, ${ }^{25}$ de manera más expresa (García el mayor, Álvaro el segundo y Alfonso el tercero), se extiende en la sucesión de García, ${ }^{26}$ afirmando que tuvo un hijo y una hija y que el hijo, también llamado García, fue el mayor, pero que por ser monje pasó el mayorazgo a su hermana, María, detallando luego la sucesión de ésta hasta el tiempo en que escribe.

Al hablar ya específicamente del cardenal, ${ }^{27}$ reitera de nuevo la opinión de Gómez de Castro sobre el origen de su nombre de bautismo (Gonzalo) y el orden de nacimiento de su hermanos, mencionando a continuación la descendencia de su hermano Juan y de los sobrinos del cardenal, ${ }^{28}$ de los que no trataremos ahora. Se extiende luego a la descendencia de sus sobrinos y habla con gran extensión de la familia materna del cardenal, la casa de la Torre. ${ }^{29}$ Tanto detalle parece indicar su relación con la familia del cardenal viva en su época, y así lo da a entender Robles al decir: otros muchos testimonios y antigüedades notables pudiera traer...ansí de los deudos del Cardenal, tanto de padre como de madre... ${ }^{30}$

Robles reitera que se le envió a estudiar gramática a Alcalá y que tras estudiar Derechos en Salamanca, ${ }^{31}$ leyó Derechos en su casa, llevando salario de los oyentes. Añade luego que oyo Philosophia y Theologia del maestro Roa. ${ }^{32}$ Respecto de su marcha a Roma, ${ }^{33}$ para procurar(se) algún beneficio, repite la historia de su accidentado viaje, ${ }^{34}$ y añade que estando en Roma ocupado en algún negocio de importancia, tuvo nueva de la muerte de su padre...y le fue forçoso bolver a su casa, alcançando primero un breve del summo Pontifice, para que por virtud del, ocupasse el primer beneficio que en su tierra vacasse. Vacó en llegando el arciprestazgo de Uzeda... y por virtud de las susodichas letras Apostólicas de hecho tomó possession del. ${ }^{35}$ Cuenta luego Robles su enfrentamiento por este motivo con el arzobispo Carrillo en términos muy similares a los de Gómez de Castro, ${ }^{36}$ relata sus prisiones en Uceda y Santorcaz y utiliza de nuevo el término muchos días como de duración de su prisión. ${ }^{37}$ Luego da la noticia del trueque del arciprestazgo por la capellanía mayor de Sigüenza, ${ }^{38}$ a partir de lo cual los datos cronológicos de nuestro cardenal están bien establecidos.

\footnotetext{
25 Ibídem, 9.

26 Ibídem, 10-12.

7 Ibídem, 16.

28 Ibídem, 17.

29 Ibídem, 28-36.

30 Ibídem, 34-35.

31 Ibídem, 37.

32 Ídem.

33 Ídem.

34 Ibídem, 38.

35 Ibídem, 38-39.

36 Ibídem, 39-41.

37 Ibídem, 41.

38 Ibídem, 42.
} 
Se advierte en Robles un mayor prurito de detalle que en Gómez de Castro, hasta el punto de que su compendio, pese a su título, es más explícito que la biografía anterior, para este periodo.

La novedad principal de la biografía de Robles es la noticia de su edad al morir, ya que dice: Fue electo Arzobispo de Toledo de edad de cincuenta y ocho años, tuvo la silla Primacial veynte y dos, y ocho meses y murió de edad de ochenta y un años. ${ }^{39}$

Hemos pasado de los aproximadamente (circiter) ochenta años, a los ochenta y uno. Y la precisión con que esto se afirma resulta convincente. Sin embargo, cabe plantearse el origen de la noticia de Robles. Da éste por sentado, en efecto, que tenía 58 años (de edad) al ser nombrado arzobispo y, como estuvo en tal cargo 22 años y 8 meses, el resultado es que cuando murió tenía al menos 80 años y ocho meses, esto es, 81 (de edad). Pero con esta deducción lo que se hace es trasladar el problema a la edad que tenía al ser nombrado arzobispo ¿Dónde consta que fue nombrado arzobispo a sus 58 años? No lo sabemos, pues Robles no dice nada al respecto, y tampoco hay en Gómez de Castro noticia de su edad al ser nombrado arzobispo.

Para terminar, podemos señalar que el cómputo que recoge Robles figura en términos idénticos en la biografía de Cisneros que formaba parte de una inédita Historia Episcopal y Real de España, ${ }^{40}$ que Baltasar Porreño debió escribir por esas fechas. ${ }^{41}$ Pese a ello, en su cronología, da Porreño como año de nacimiento $1437 .{ }^{42}$

La cuarta (y última) biografía clásica del cardenal Cisneros es la de Quintanilla, de la que ya hemos hablado. Era Quintanilla un franciscano de Alcalá que fue nombrado postulador en Roma de la causa de beatificación del cardenal, cuyo proceso canónico se inició en Toledo en 1626. A tal fin, Quintanilla se trasladó a Roma, donde residió entre 1650-59, y en el curso de esa estancia y con la finalidad de exaltar los méritos de Cisneros escribió esta obra. De notable barroquismo y discutible ordenación, la obra de Quintanilla es, después de la de Gómez de Castro, la biografía más influyente de Cisneros, aunque tenga innegable finalidad hagiográfica. Por lo demás, esto tiene su vertiente positiva, pues al ser ya por entonces el proceso de beatificación una causa jurídica, hay en ella un prurito de precisión, incluso cronológica, que resulta útil, aunque sea inexacta. Como hemos dicho al inicio, es la que fija la versión tradicional de la biografía del cardenal que, en lo relativo a la cronología de sus primeros años, no va a variar sustancialmente en los tres siglos y medio posteriores.

En la epístola prohemial dedicatoria que precede a la biografía propiamente dicha, ${ }^{43}$ se incluye una larga disertación sobre el linaje del cardenal. No nos detendremos salvo

\footnotetext{
39 Ibídem, 201.
}

40 Editada en Dos tratados históricos tocantes al Cardenal Ximénez de Cisneros (Sociedad de Bibliófilos españoles, Madrid, 1918): 213.226.

41 Vid. la Introducción del conde de Cedillo (pp. XIV-XV) a los Dos tratados... según la cual, escribió su obra no más tarde de 1606.

42 Porreño, 1918: 224.

43 Quintanilla. P. 1653. Archetypo de virtudes, espejo de prelados, el venerable padre y siervo de Dios Fray Francisco Ximénez de Cisneros: Epístola prohemial, 2-34. Palermo, Nicolás Bua, impr. en lo que es útil a nuestros efectos, a saber, lo que en ella se dice de los antepasados más inmediatos del cardenal, de los que más adelante trataremos. Sólo señalaremos ahora que la genealogía que da Quintanilla no carece, como era el caso de las anteriores, de fechas, todo lo contrario, abundan en ella, lo que nos va a ser muy provechoso. Señalemos ahora sólo que en ella da Quintanilla la fecha de muerte de la madre de Cisneros (que sitúa en 1482). ${ }^{44}$

De esta larga obra nos interesan en primer lugar los cuatro primeros capítulos del Libro I, en los que se relatan los años cuya cronología discutimos.

Menciona previamente Quintanilla sus fuentes, ${ }^{45}$ y específicamente hace referencia a las biografías de Alvar Gómez de Castro y de Eugenio de Robles. Y tras indicar la forma utilizada para citarlas, añade: $Y$ se note que en el primer libro aun carece destas citas, porque todo lo que ay escrito en el, es caso comun, que corre en todos los que an escrito su vida, y en todos los testigos de su Beatificación. ${ }^{46}$

Empieza pues Quintanilla afirmando lo que sus predecesores omiten (o sólo dan indirectamente): que nació en Tordelaguna (Torrelaguna) en $1436 .{ }^{47}$ Respecto a sus estudios, Quintanilla adopta la versión de Gómez de Castro, ${ }^{48}$ según la cual fue, pasados los siete años, enviado a Cisneros a casa de su tío García, auque fuera su otro tío Álvaro, al que califica de presbítero (en contradicción esta vez con Gómez de Castro) quien le enseñó allí. Vuelto a su casa, siendo ya de diez años, ${ }^{49}$ fue enviado a Alcalá a estudiar Gramática, y tras volver a Torrelaguna (siendo de catorce años) fue enviado a Salamanca. ${ }^{50}$ Estudió allí Leyes y Cánones durante cinco años y graduose de bachiller en el sexto año. Dados sus méritos, le buscaba casi toda la escuela, y porque leya en su casa las leyes y pasava a los más estudiantes. En este exercicio, y siendo pasante estuvo tres años. ${ }^{51}$ Pero no se contentó con esto y oya cada día una lición de Philosophia y otra de Theologia, esta de un maestro famoso Catedratico de la referida universidad, que llamaban Maestro Roa. ${ }^{52}$

Siendo ya de 22 años, quando acababa de pasar para graduarse Licençiado en Canones, ${ }^{53}$ le llamaron sus padres y lo dejó todo. Marchó a Roma, precisa Quintanilla, por los años de $1459 .{ }^{54}$ Cuenta con brevedad las incidencias de su viaje, y se detiene algo más en su estancia en Roma donde, dice, abogava. ${ }^{55}$ Allí se ordenó sacerdote y, como en versiones anteriores, la muerte de su padre motivó su vuelta a España, tras una estancia en Roma (y esto es novedad de Quintanilla) de más de seis años. ${ }^{56}$ Por si no estuviera claro, reitera luego que llegó a Torrelaguna por los años de 1465,57

\footnotetext{
44 Ibídem., 32.

45 Ibídem, 40.

46 Ibídem, 42-43.

47 Ibídem, L. I, 5.

48 Ibídem, L. I, 6.

49 Ídem.

50 Ibídem, L. I, 7.

51 ídem.

52 Ídem.

53 Ibídem, L. I, 8.

54 Ídem.

55 Ídem.

56 Ídem.

57 Ibídem, L. I, 9.
} 
provisto de la famosa bula expectativa que ya hallamos en biografías anteriores. De un documento, anteriormente citado, $^{58}$ en el que se le otorga una capellanía en 1473 deduce Quintanilla que no era aún en esa fecha arcipreste de Uceda, ${ }^{59}$ por lo que infiere que la vacante de Uceda no se habría producido hasta $1473,{ }^{60}$ y que su prisión por Carrillo se produjo inmediatamente después. El relato de ésta es similar al de fuentes anteriores con alguna variante, la más sustancial, que precisa el lapso de duración que fija en más de seis años (en vez de los muchos días de las fuentes anteriores), ${ }^{61}$ con lo que la consiguiente permuta del arciprestazgo por la capellanía mayor de Sigüenza, fechada en 1480 resulta así más congruente.

Lo que sigue de la vida de Cisneros ofrece menor interés para nuestro análisis, pero el libro de Quintanilla contiene algunas cosas interesantes más.

La 1 ạ es la reproducción de un breve de León $X_{\text {, }}^{62}$ fechado el 31-V-1517, en el que le ordena relaje las penitencias que se infligía, habida cuenta de su edad y estado de salud. Lo interesante para nosotros es que en el punto 2 del breve se dice: Accepimus quod tu, qui septuagessimum \& ultra tuae aetatis annum agis. Una traducción simple de esta frase sería que dice que era mayor de 70 años, cosa que Quintanilla comenta, con notoria superficialidad, diciendo: Sabe su Santidad que tenía más de setenta años, es verdad, que ya tenía cumplidos ochenta, como se verá después. ${ }^{63}$ Pero dejamos el comentario del breve y de su traducción para más adelante.

Aún vuelve Quintanilla a la cuestión de la edad de Cisneros, tras relatar con minuciosidad su última enfermedad y muerte, mencionando la edad que tenía según diversos autores, que oscila entre los cerca de 80 que daba Gómez de Castro y los 84 que le asignan Garimberti y Vittorelli. ${ }^{64}$ Él por su parte apostilla que lo más cierto es que tuvo cumplidos ochenta y un años, sin justificar su afirmación sino por la concordancia aproximada de varios autores antiguos, que ya hemos mencionado.

En resumen, la aportación principal de Quintanilla es fechar de manera en apariencia lógica sus primeros años de vida. Como luego veremos, esa aparente congruencia la ha destruido la aparición posterior de diversos documentos, pero al menos ahora tenemos una cronología relativamente clara, aunque no por serlo es exacta.

No es esto lo único que escribió Quintanilla sobre Cisneros, pero sí lo único que publicó. En 1668 redactó unas Memorias de Tordelaguna, que recoge interesantes noticias utilizando un Libro de testamentos y escrituras confeccionado hacia 1600, pero que recoge documentos de la 2a mitad del s. XV, y el Registro original de cuentas de la villa de Tordelaguna correspondiente al periodo 1470-1500. En

58 En la Epístola prohemial, 32.

59 Lo que sería lógico si en el documento que cita (que es de 1580) se afirmase esto, pero en él (según la transcripción de Quintanilla) sólo se dice que parece que el año de 1473.

60 Ibídem,. L. I, 9.

61 Ibídem, L. I, 10.

62 Ibídem,.., L. IV, 280 y ss.

63 Ibídem,. 280.

64 Libro IV, capítulo XIV, 303. él hay algunas noticias que contradicen la versión anterior del propio Quintanilla. Pero estas Noticias sólo nos han llegado tres siglos después, y por ello las tratamos más adelante.

Un continuador de Quintanilla en la obra de beatificación del cardenal Jiménez de Cisneros, Pedro Fernández del Pulgar, escribió un libro sobre éste, netamente hagiográfico, pero precedido por una corta biografía. Aunque sólo a título de curiosidad, señalaremos que modifica algo la cronología que da Quintanilla para los primeros años del cardenal. Así, dice que comenzó sus primeros científicos rudimentos en 1448 y que fue en 1452 cuando pasó a la Universidad de Salamanca. ${ }^{65}$ Todo ello, claro está, partiendo de que nació en 1436.

Apenas mencionaremos las obras posteriores, relativamente numerosas, que desde mediados del s. XVII hasta el s. xx han tratado de la persona de Cisneros. En conjunto, todas ellas reiteran, para el periodo que nos interesa, lo ya escrito por los autores que hemos analizado y, en general, reconocen de manera expresa su deuda con ellos.

Así, la biografía de Esprit Fléchier, ${ }^{66}$ que es probablemente la más prestigiosa, cita expresamente la de Gómez de Castro y sigue punto por punto la trama biográfica ya convertida en tradicional, casi sin fechas, y con apenas alguna añadidura de su cosecha que no son sino ilustraciones (injustificadas) de las versiones anteriores. ${ }^{67}$ Es cierto que Fléchier sitúa en 1437 el nacimiento de Cisneros, ${ }^{68}$ pero esto no obsta para que reitere que murió a veinte y dos años de su Prelacía y ochenta y uno de su edad. ${ }^{69}$ En realidad, es Fléchier quien, según el sistema antiguo de cómputo, tiene cierta razón, frente a Quintanilla. No teniéndose constancia de la fecha de su nacimiento, la expresión de que tenía ochenta y un años (de su edad) significaba que murió de 80 cumplidos, y al morir el 8 de Noviembre, habría nacido o en los meses finales de 1436 o en los diez primeros meses de 1437, siendo esto último lo más probable. Es verdad que Quintanilla afirma, taxativamente, que murió de 81 años cumplidos, pero esto, sin conocer la fecha de nacimiento, es una afirmación muy arriesgada.

Aún podemos señalar la cuestión de la diferente transcripción (y traducción) del Breve de León $\mathrm{X}$ al que hemos aludido al hablar de Quintanilla. De momento sólo diremos que

\footnotetext{
65 Fernández del Pulgar, P. 1673. Vida y motivos de la común aclamación de santo del venerable siervo de Dios D. Fr. Francisco Ximenez de Cisneros...: 3. Madrid. Vda. de Melchor Alegre.

66 Histoire du cardinal Ximènes (París, 1693) traducida al español por Miguel Franco de Villalba (Zaragoza, 1696) como Historia de el señor Cardenal Don. Francisco Xmenez de Cisneros. El éxito de esta obra es visible por la cantidad de reediciones en diversos idiomas, especialmente en español, a lo largo de los siglos posteriores.

67 Así dice que Cisneros fue en Roma abogado consistorial, o que la vacante del arciprestazgo de Uceda se produjo por muerte de su titular, etc.

68 La errata de la 1ạ edición francesa, en la que figura 1457, dio lugar a una crítica poco motivada de Prescott, que aquí no tomamos en cuenta.

69 Fléchier, E. 1696. Historia de el señor Cardenal Don. Francisco Xmenez de Cisneros: 417. Zaragoza. Pascual Bueno. La 22 année de son Episcopat \& la 81 de son âge, en la edición original francesa (Vol. 2, 267).
} 
mientras la traducción española se ajusta al texto latino, ${ }^{70}$ la versión francesa es notoriamente abusiva. ${ }^{71}$

Poco interés tienen otras biografías francesas, como la de Marsollier, ${ }^{72}$ o españolas como la de Navarro y Rodrigo. ${ }^{73}$ Incluso la de un notable historiador y teólogo como Hefele no aporta novedad alguna al periodo objeto de nuestro estudio. ${ }^{74}$ Cita éste expresamente a Quintanilla al dar la fecha de 1436 como la de nacimiento del cardenal, ${ }^{75}$ y sigue en todo la versión tradicional que no repetimos de nuevo para no cansar al lector. Señalemos sin embargo una obra de fines del s. XVIII que, sin ser propiamente una biografía de Cisneros, resulta, si no interesante, al menos curiosa. Nos referimos a la historia del Colegio Mayor de los SS. Pedro y Pablo, escrita por Nicolás Aniceto Alcolea, cuya primera parte contiene una biografía de Cisneros de regular extensión (casi 150 páginas). La misma sigue, como es lógico, la versión tradicional, citando expresamente a Robles y a Quintanilla, aunque también a otras fuentes franciscanas, como los anales de Wadding. ${ }^{76}$ Recoge por tanto su estudio en Alcalá y Salamanca, su viaje a Roma y su vuelta a España en 1465 por muerte de su padre, de conformidad con la versión tradicional.

Sin embargo, introduce en ésta una variante que no recogen Robles ni Quintanilla, y es que Carrillo le nombró Visitador del partido de Uceda. ${ }^{77}$ ¿Conocía Alcolea la obra de Vallejo? Sin duda, pues le cita expresamente. ${ }^{78}$ Pero es de notar que no copia literalmente lo que éste dice al respecto y da un nombre castizo (visitador) al cargo que Vallejo describe en forma compatible con este título. ${ }^{79}$ Señalemos, en fin, que reproduce, ${ }^{80}$ en versión castellana, el breve de 31 de Mayo de 1517 que ya hemos mencionado al hablar de Quintanilla. A subrayar, como en el caso de Fléchier la versión tendenciosa que da del mismo y que luego comentaremos. También es digno de señalarse que dice haber

\footnotetext{
70 Ibídem, 457.

71 Fléchier, E. 1693. Histoire du cardinal Ximènes : II, 350. Paris, chez Jean Anisson.

72 Jacques Marsollier: Histoire du ministère du cardinal Ximenez (2 vols., París, 1704).

73 Carlos Navarro y Rodrigo: El cardenal Cisneros. Estudio biográfico (Madrid, 1869).

74 Karl J. von Hefele: Der Kardinal Ximenes um die Kirchliche zustände Spaniens am Ende des 15 und Anfange des 16 Jahrhunderts (Tubinga, 1851). Citamos por la traducción española de 1869.

75 Hefele, K. 1869. El Cardenal Jiménez de Cisneros y la I I lesia española a fines del S. XV y principios del XVI: 13. Barcelona. Imprenta del Diario de Barcelona.

76 Cuyos Annales minorum se editaron inicialmente en Lyon a partir de 1625

77 Alcolea N.A. 1777. Seminario de nobles, taller de venerables y doctos, el Colegio Mayor de S. Pedro y S. Pablo, fundado en la Universidad de Alcalá de Henares para trece religiosos de todas las provincias Observantes de N. P. S. Francisco de estos Reynos por el Emmo. y Ven. Cardenal de España mi Señor, D. Fr. Francisco Cisneros, lustre de toda la religión seráfica, con su admirable vida): 6. Madrid. Imprenta de Manuel Martín.

78 Ibídem., 43.

79 Esta expresión de visitador se utiliza también por otros autores como Esteban Azaña (Historia de la ciudad de Alcalá de Henares, I, 1882, p. 233).

80 Alcolea, N.A. 1777: 115-17.
}

recogido la versión de Wadding, ${ }^{81}$ según él mismo afirma. ${ }^{82}$ En fin, se hace eco Alcolea de la versión popular, que las biografías clásicas sólo insinúan, según la cual fue Cisneros envenenado (que murió el Santo Cisneros envenenado con una Trucha grande que en Borceguillas le dieron). ${ }^{83}$

\section{HISTORIOGRAFÍA MODERNA}

El siglo xx significa en la historiografía cisneriana en primer lugar la publicación de escritos y documentos que perfilan su biografía. Ya hemos mencionado la edición en 1913 del Memorial de Vallejo, obra de Antonio de la Torre y del Centro de Estudios Históricos de la Junta de Ampliación de Estudios. Pocos años después se publica, en un artículo de Jose Ma Pou y Martí, ${ }^{84}$ el texto de la bula de provisión del arciprestazgo de Uceda que, a medio plazo, va a revolucionar la historiografía tradicional de Cisneros, y de momento supone la quiebra de la vieja versión de la bula expectativa que daban los biógrafos clásicos.

Por el contrario, no tienen especial valor a nuestros efectos las biografías extensas que se publican en el primer tercio del siglo XX, unas porque, como la del conde de Cedillo, ${ }^{85}$ se limitan a un periodo de tiempo muy alejado del que nos interesa, y otras como la de Lyell, ${ }^{86}$ o la del P. Fernández de Retana, ${ }^{87}$ porque no aportan novedad a la versión tradicional, cuando no incurren en inexactitudes. Señalemos tan sólo de pasada que este último supone que Cisneros iría a Alcalá a los 12 años, ${ }^{88}$ por ser ésta la edad clásica y tradicional y que iría a Salamanca a los 15 años; ${ }^{89}$ creeque allí recibió en privado lecciones de Teología del maestro Roa,90 y trata aún de conciliar la bula de provisión del arciprestazgo de Uceda con una bula expectativa anterior. ${ }^{91}$ En fin, la referencia que hace del breve de León $X$ da de éste una versión poco exacta..$^{92}$

Como hemos visto al inicio, incluso la biografía, no por resumida menos importante, que en 1972 da García Oro en el Diccionario de Historia Eclesiástica de España conserva mayoritariamente los rasgos de la versión tradicional, pese a que en ella ya se ha modificado la versión relativa a la bula de Uceda.

Poco después, aún se hacían públicos documentos inéditos, si no relativos a Cisneros mismo, sí a su familia, que modifican aún más la versión tradicional de la biografía

81 Cuyo texto latino no difiere del de Quintanilla. Cfr.. Wadding, L. 1736. Annales minorum, XVI, 37.

82 Alcolea, N.A.1777: 117

83 Ibídem, 122.

84 "El Cardenal Cisneros, arcipreste de Uceda" en Archivo Ibero Americano 13: 413-17.

85 Jerónimo López de Ayala y Álvarez de Toledo, conde de Cedillo: El cardenal Cisneros, gobernador del reino (2 vols., Madrid, 1921).

86 James P.Lyell: Cardinal Ximenes (Londres, 1917).

87 Luis Fernández de Retana: Cisneros y su siglo (1929-30).

88 Fernández de Retana, L. 1929-30. Cisneros y su siglo (1929-30) I, p. 38. Madrid. Administración del Perpetuo Socorro.

89 Ibídem, I, 42.

90 Ídem.

91 Ibídem, I, 63.

92 Ibídem, II, 353: "a pesar de su edad tan avanzada", versión que, claro está, no pretende ser literal. 
de nuestro personaje. Aparecen en un artículo que publica Juan Meseguer sobre la familia del cardenal Cisneros, ${ }^{93}$ utilizando las ya aludidas Noticias de Tordelaguna que redactó Quintanilla en 1668, pero que nunca se publicaron. Este artículo desmiente algunas de las afirmaciones de la versión tradicional relativas a la familia del cardenal, precisa la cronología de algunos sucesos, todo ello basado en el trabajo de Quintanilla y las fuentes que utiliza éste, contemporáneas del cardenal. En particular, señalemos que, al fijar la muerte del padre del cardenal en 1488, priva de fundamento a la historia tradicional que lo hacía regresar de Roma en 1465 por tal causa. Otros aspectos y precisiones que proporciona este artículo los analizamos más adelante, pues los datos que aporta se incorporan por García Oro a su posterior biografía del cardenal.

Porque en efecto, la gran biografía del cardenal Jiménez de Cisneros en el siglo xx la publica, ${ }^{94}$ algo tardíamente, en 1992, García Oro.

Se inicia esta obra con un análisis de los ascendientes de Cisneros que, en lo que se refiere a los más inmediatos (a partir de su bisabuelo), confirma en lo sustancial lo afirmado por la versión tradicional y específicamente por Quintanilla, con alguna apoyatura documental. Mencionaremos más adelante las noticias y deducciones que hace García Oro respecto de estos parientes del cardenal, que ahora dejamos de lado.

Aproximándonos más a Cisneros, afirma García Oro que el matrimonio de sus padres se realizó probablemente hacia 1430,95 aunque reconoce que sólo veinte años más tarde aparecen desempeñando papeles importantes en la villa. Dejando de lado la cuestión de su importancia municipal, lo que esto parece significar es que sólo hacia 1450 aparecen documentados en Tordelaguna sus padres. Y en efecto, consta que Alfonso fue regidor de la villa en 1453.

Mantiene García Oro que el cardenal nació en 1436, afirmación que matiza diciendo que es una fecha probable, imposible de comprobar. ${ }^{96}$ Pero añade luego que esta fecha se acomoda bien con otras noticias seguras sobre su edad en el momento de realizar algunas de sus empresas y sobre todo a la hora de la muerte. ${ }^{97}$ Sugiere, incluso, el día de nacimiento con una afirmación hipotética, según la cual, atendiendo al nombre recibido en el bautismo, cabría pensar que hubiese nacido el 10 de enero...San Gonzalo. Esto contrasta con las opiniones, ya mencionadas, de Gómez de Castro y Robles sobre el origen de dicho nombre..$^{98}$

García Oro sitúa (siempre en un tono hipotético) los estudios del niño Gonzalo en su casa, ${ }^{99}$ bajo la dirección de su tío Álvaro, considera menos probable que fuera a Cuéllar (como afirma Vallejo) y posible que acudiera a Alcalá (como afirman los otros tres). Coincide García Oro con la cronología de

93 "Noticias sobre el cardenal Cisneros, sus padres y parientes" en Archivo Ibero Americano, 34: 287-97.

94 El cardenal Cismeros Vida y empresas.

95 García Oro, J. 1992. El cardenal Cismeros Vida y empresas. I, 11 Madrid, B.A.C.

96 Ibídem, 18.

97 Ibídem, 18-19.

98 Ibídem, 19.

99 Ibídem, 21.
Quintanilla respecto de su marcha a Salamanca, al afirmar que lo hizo finalizado el decenio de 1440 y añade que estudió allí aproximadamente en los años 1450-60. ${ }^{100}$ También coincide con Quintanilla en fechar hacia 1456 su graduación como bachiller, afirmando que parece seguro que no abandonó Salamanca sino que prosiguió sus estudios. ${ }^{101}$ En realidad, según García Oro, que emplea a menudo el potencial, ejercería alguna cátedra cursatoria entre los años 1456-59.

Señalemos una omisión significativa. Al hablar de los hipotéticos maestros que habría tenido en Salamanca, no menciona García Oro al maestro Roa, ${ }^{102}$ y en cambio parece reprochar a sus biógrafos que no se hubiesen preocupado de averiguar qué maestros tuvo. Hay que entender que es una errata (más que una incongruencia) su afirmación de que partió de Salamanca, al final de los años sesenta, ${ }^{103}$ sobre todo porque en la misma página se le sitúa en tierras toledanas en el decenio 1460-70. En fin, acepta la versión de Vallejo sobre su nombramiento como corregidor de Uceda, en una fecha desconocida de estos años. ${ }^{104}$

No nos detendremos en la historia de la bula, que García Oro narra según lo hizo en su artículo biográfico del Diccionario de Historia Eclesiástica. Esto no habría impedido, según el mismo, una estancia romana, que cabe situar en 1470. ${ }^{105}$ En cuanto al conflicto con Carrillo, se sigue expresamente la versión de Vallejo, reiterando la frase de éste de que su prisión duró "muchos días". ${ }^{106}$ Los largos años de cárcel de la versión tradicional que el propio García Oro suscribía en 1972 se ven ahora recortados por el hecho, documentado, de que Cisneros ejerció como arcipreste de Uceda entre 1471 y 1476 . Se adelanta al otoño de este año su marcha a Sigüenza, donde a fines de 1476 ya es capellán mayor. ${ }^{107}$

No parece necesario, a los efectos de nuestra investigación, seguir con esta obra de García Oro. El autor ha publicado después otras dos biografías que reiteran los datos principales de la anterior, aunque ofrecen alguna variante y muestran, si cabe, una mayor vaguedad e imprecisión en la cronología. ${ }^{108}$ En ellas mantiene la fecha de nacimiento en 1436, en términos muy similares, pues la califica de imposible de verificar, pero no contradictoria. ${ }^{109}$ Aunque no se da fecha de su marcha a Salamanca, se afirma en la primera que a mediados del decenio de los cincuenta está ya allí, ${ }^{110}$ mientras que en la segunda se dice que llegó hacia $1450 .{ }^{111}$ No se precisa cuándo volvió a su tierra. Incongruentemente (habida cuenta de la fecha de nacimiento que se mantiene), se afirma que a mediados del decenio de 1460 cumplía sus veinticinco años y que para entonces ya estaba en su tierra. ${ }^{112}$

\footnotetext{
$100 \quad$ Ibídem, 22.

101 Ibídem, 26.

102 Ibídem, 27.

103 Ibídem, 28.

104 Ibídem, 28, n. 51.

105 Ibídem, 30.

106 Ibídem, 31.

107 Ibídem, 32.

108 García Oro, J. 2002: Cisneros, Barcelona. y García Oro, J. 2005: Cisneros, un cardenal reformista en el trono de España. Madrid.

109 García Oro, J. 2002: 27. Barcelona, Ariel.

110 Ibídem, 29.

111 García Oro, J. 2005: 37. Madrid, La Esfera de los Libros.

112 Ibídem, 33.
} 
Aunque se omite en la biografía de 2002 toda referencia al viaje a Roma, en la de 2005 se repite casi literalmente lo dicho en la de 1992. ${ }^{113}$ Aún ha publicado García Oro en 2011 el artículo biográfico sobre el cardenal Jiménez de Cisneros en el Diccionario Biográfico Español, en el que no se aparta apenas de lo antedicho. Reitera en él que nació en 1436, según los cálculos más seguros, y mantiene la indefinición sobre el lapso de tiempo comprendido entre que regresó a su tierra de Torrelaguna (hacia 1460) y su nombramiento como arcipreste de Uceda, del que, curiosamente, no da la fecha. No menciona en él, por lo demás, su nombramiento como corregidor anterior al de arcipreste.

Las biografías de García Oro son probablemente la mayor aportación de la historiografía moderna a la figura del cardenal Cisneros en los últimos tres siglos. En realidad, con la publicación a lo largo del s. xx de varios documentos que iluminan aspectos oscuros de la biografía del cardenal, deberían ser la síntesis definitiva de la misma, pero, a nuestro juicio, su labor se ve hipotecada por la cuestión de la fecha de nacimiento, que le impide dar cuenta de un lapso temporal considerable de la vida del cardenal, y, peor aún, que parece forzar al biógrafo a adoptar una actitud de imprecisión y vaguedad, no exenta de omisiones significativas, que pone en cuestión el rigor de su obra en lo que se refiere a estos años primeros de la vida del cardenal.

En cualquier caso, y siempre en lo referente a este periodo, la obra de García Oro no resulta satisfactoria, y su tratamiento de la cronología del mismo no tiene carácter crítico.

En los últimos años se han publicado un par de monografías que, sin ser propiamente biografías de Cisneros, tratan de su figura y trazan semblanzas del mismo. Al ser obras de autoras anglosajonas, publicadas en inglés, se diría que contemplan la biografía de Cisneros con una visión más crítica, aunque en la cronología sigan la versión tradicional.

Se trata, en primer lugar, de una obra de Erika Rummel. ${ }^{114}$ Aunque se ocupa poco de su biografía, no deja de señalar la falta de evidencia documental sobre su fecha de nacimiento, ${ }^{115}$ ni deja de plantear cronológicamente la cuestión de su relación con el maestro Roa. También señala como dudosa la versión tradicional de su viaje a Roma, añadiendo que presenta dificultades cronológicas. ${ }^{116}$ Por lo demás, recoge ya, claro está, el verdadero carácter de la bula de nombramiento como arcipreste de Uceda, y registra ya a Cisneros como capellán mayor de Sigüenza en 1476. ${ }^{117}$

Más importante es el esbozo biográfico que contiene el capítulo 1ㅇ de la obra de Erika Dolphin. ${ }^{118}$ Tras pasar revista a sus primeros biógrafos, la autora pone de relieve el carácter panegírico de sus obras, ${ }^{119}$ una observación que extiende a

\footnotetext{
113 Ibídem, 42: una estancia romana que cabe situar en 1470.

114 Jiménez de Cisneros: On the Treshold of Spain's Golden Age..

115 Rummel, E. 1999. Jiménez de Cisneros: On the Treshold of Spain's Golden Age: 11. Tempe. Arizona Center for Medieval and Renaissance Studies.

116 Ibídem, p. 12.

117 Ibídem., p. 14.

118 Archbishop Francisco Jiménez de Cisneros and the Decoration of the Chapter Room and Mozarabic Chapel in Toledo Cathedral.

119 Dolphin, E. 2008. Archbishop Francisco Jiménez de Cisneros and the Decoration of the Chapter Room and Mozarabic Chapel in Toledo Cathedral: 12. Ann Arbor, Michigan. ProQuest.
}

autores posteriores, incluidos los del S. $x x .{ }^{120}$ Sin poner en cuestión la fecha tradicional de su nacimiento, subraya la ausencia de documentos que registren su actividad anterior a $1471 .{ }^{121}$ Deduce de la versión de Quintanilla que habría permanecido en Roma unos 10 años (1459-69), puesto que sabemos modernamente que su padre no murió en 1465 como decía Gómez de Castro y recogía la versión tradicional. ${ }^{122}$ Su tratamiento del caso del maestro Roa, muy detallado e interesante, lo dejamos para más adelante. Por lo demás, da una versión similar a las de las obras de Rummel y García Oro sobre la bula que le otorgó el arciprestazgo de Uceda y respecto de la fecha de su pase a Sigüenza.

Como conclusión, cabe decir que si la Historiografía moderna ha aclarado el verdadero sentido de la bula de provisión del arciprestazgo de Uceda, y ha minimizado (hasta casi hacerlo desaparecer) tanto el viaje de Cisneros a Roma como su prisión, no ha sabido resolver satisfactoriamente el lapso de tiempo así generado, que es el que va desde la presumible fecha de terminación de los estudios en Salamanca (1459) hasta la ocupación de un cargo en Uceda (1471). La historiografía clásica, sobre todo en la versión canónica de Quintanilla, había construido una cronología que, al basarse en premisas falsas (la estancia de seis años en Roma, la muerte de su padre en 1465 , los seis años de prisión) ahora es insostenible y no se ha sustituido sino con conjeturas carentes de documentación.

Por eso, para resolver el problema que hemos planteado, precisamos una nueva aproximación a la cronología del cardenal, que realizamos en los apartados siguientes.

\section{APROXIMACIÓN CRONOLÓGICA. INDICACIONES PREVIAS}

Son sabidos los problemas que plantea el tratar de establecer una cronología, siquiera sea aproximada, en la época medieval, e incluso hasta bien entrado el s. XVI. Estos problemas, que radican en gran parte en la ausencia de registros fehacientes, se agravan cuando lo que se trata de establecer es una fecha de nacimiento. Salvo en el caso de los reyes y la alta nobleza, la determinación, siquiera sea aproximada, de la fecha de nacimiento de un personaje cuyo encumbramiento se producirá sólo varias décadas después, es tarea ardua, casi imposible.

Por ello, es normal que en estos casos se supla la ausencia de datos por una constancia tradicional, de origen incierto y dudosa fiabilidad. Porque la mentalidad antigua tiende a desdeñar la precisión cronológica, y a antedatar los nacimientos, al atribuir a menudo a los personajes relevantes una edad superior a la verosímil.

Sin salirnos del ámbito de la Historia eclesiástica y del siglo $\mathrm{XV}$, son notorios ejemplos de lo dicho el caso de Benedicto XIII, cuya edad probablemente fue aumentada por su contemporáneo Alpartil (aunque quizá no tanto como dice Moxó), el del cardenal Ram (muerto en 1445) que, según la cita que da Chacón de su epitafio, murió casi

\footnotetext{
120 Ibídem, 14.

121 Ibídem, 15.

122 Ibídem, 16.
} 
centenario (aetatis suae centesimo vel circa), ${ }^{123}$ o el del portugués Jorge da Costa (muerto en 1508) cuyo epitafio en Santa Maria del Popolo reza ann. agens secundum supra centesimum. ${ }^{124}$ Esto indica, sin duda, que los contemporáneos de estos prelados daban por cierta esa edad, cosa que no garantiza en absoluto su exactitud. Incluso en siglos posteriores persiste esta tendencia, que se observa aún en el caso tardío del cardenal Trejo (muerto en 1630), cuya fecha de nacimiento tradicional se antedata también unos 15 años.

Se observará que los casos citados antedatan el nacimiento entre diez y veinte años, esto es, retrotraen al personaje en cuestión a una generación anterior a la que, por su nacimiento más probable, debieron pertenecer. No se trata, por tanto de intentar precisar día y mes, ni siquiera año, de nacimiento, sino de situar al personaje en el contexto generacional al que verosímilmente pertenecía

Con estas reservas, sin embargo, no hay mayor dificultad en admitir las versiones tradicionales, siempre que se tengan en cuenta, además del carácter siempre aproximado de las mismas, al menos estos dos criterios:

1ㅇ) Que su admisión no contradiga otros datos cronológicos fidedignos. Por poner sólo un ejemplo próximo a Cisneros, la versión tradicional de la fecha de nacimiento (1475) del futuro cardenal Quiñones que da Fray Andrés de Guadalupe, ${ }^{125}$ y que reitera el artículo biográfico dedicado al mismo en el Diccionario de Historia Eclesiástica, ${ }^{126}$ es contradictoria con el testimonio del Memorial de Vallejo que presenta al entonces todavía Enrique de Quiñones como paje del arzobispo Cisneros en $1498,{ }^{127}$ y por ello no puede sostenerse.

2) Que no afecte a la coherencia biográfica del personaje. Con esto queremos decir que, aunque no haya una contradicción cronológica flagrante, como en el caso anterior, la biografía del mismo se resienta de incongruencias y contradicciones menores, salvables sólo a base de excluir indicios o acumular imprecisiones.

Es obvio que la biografía tradicional de Cisneros no incurre en una contradicción cronológica insalvable. Pero esto es porque apenas hay fechas que podamos confrontar con ella antes de 1471, y las que se refieren a otros personajes próximos pueden explicarse (sin certeza alguna, por lo demás) por diversas causas, más o menos hipotéticas. Pero, incluso en la versión adoptada modernamente por García Oro, la

123 Ciaconius, A. 1677. Vitae et res gestae Pontificum Romanorum et S. R. E. Cardinalium ab initio nascentis Ecclesiae, usque ad Urbanum VIII: II col.832. Roma. Philippi et Ant. De Rubeis.

${ }^{124}$ Forcella, V.1869. Iscrizioni delle chiese e d'altri edificii di Roma dal Secolo XI fino ai giorni nostri: I, 333 n.1267. Roma. Tipografia delle Scienze Matematiche e Fisiche.

125 Guadalupe, A.1662. Historia de la Santa Provincia de los Ángeles, de la regular Observancia y Orden de nuestro seráfico Padre San Francisco: 219. Madrid. Mateo Fernández. 219.

126 García, I. 1973. Quiñones, Francisco de los Ángeles, en Q. Aldea (Dir.), Diccionario de Historia Eclesiástica de España, III, 2037-2038 Madrid. CSIC.

127 Vallejo, J. 1913: 25. biografía de Cisneros sigue presentando un lapso de tiempo no bien justificado (grosso modo, la década transcurrida entre 1460 y 1470) y las contradicciones e incongruencias que presenta no se salvan por el biógrafo sino omitiendo (y por ende, negando implícitamente) datos consignados por los biógrafos tradicionales, con la principal finalidad de salvar una cronología que, precisamente, sólo descansa en la afirmación de dichos biógrafos.

Sin duda, hasta las biografías mejor documentadas pueden presentar alguna incongruencia menor, sin que eso afecte a la sustancia cronológica de la misma. Pero ante una cronología carente de documentación que la sustente, la acumulación de datos contradictorios o incongruentes plantea la necesidad de una revisión, que es lo que tratamos de hacer con este trabajo.

Las principales contradicciones que afectan a la cronología tradicional de Cisneros se refieren a la cronología de su familia y a ciertos hechos que se relatan de su vida, que (de aceptarse) resultan incompatibles con la fecha tradicional que se da como de su nacimiento. Es probable que algunos de esos hechos no sean ciertos, pero la negación de todos ellos resulta menos verosímil que la lisa y llana aceptación de que su fecha de nacimiento está antedatada.

\section{Cronología familiar de Cisneros}

Con respecto a sus antecedentes familiares es Quintanilla, en la epístola prohemial dedicatoria que abre su ya citado Archetypo, ${ }^{128}$ el que detalla más la cronología de sus antepasados. Dejando de lado los más lejanos, iniciaremos la indagación en el que fuera bisabuelo paterno del cardenal, Juan Ximénez de Cisneros, que nació por los años de $1370,{ }^{129}$ según Quintanilla. De él se nos dice que dexo solo un hijo que se llamó D. Toribio Ximénez de Cisneros, ${ }^{130}$ quien nacio en tiempo de $D$. Enrique el tercero (esto es, después de 1390) y murio como caballero en la batalla de Olmedo año de 1445.

La fecha de la batalla de Olmedo, que García Oro precisa (29 de mayo de 1445), es la primera que nos resulta por un lado cierta y por otro significativa. La certeza, obviamente, afecta a la fecha misma de la batalla, no tanto a la muerte en la misma del abuelo del cardenal, que Fernández de Retana y García Oro admiten sin darla por segura. ${ }^{131}$ Los autores anteriores a Quintanilla no mencionan esta muerte. Vallejo no menciona a Toribio Jiménez, y Gómez de Castro apenas lo nombra, ${ }^{132}$ sin dar detalle ni de su vida ni de su muerte. La mención de Robles es un poco más amplia, pero no dice nada sobre su muerte. ${ }^{133}$

Lo significativo de esta fecha no es ya que pueda indicar la posible edad (seguramente no muy avanzada) del abuelo del cardenal, sino que cabe ponerla en relación lógica con

128 Quintanilla, P. 1653. pp.1-34.

129 Ibídem, p. 19.

130 Ibídem, pp. 19-20.

131 "al parecer" dice Fernández de Retana, L. 1929: I, 28; "habría fallecido" dice García Oro, J. 2005: 27.

132 Gómez de Casto, A. 1569: f. 1.

133 Robles, E. 1604: 9. 
el pasaje de Gómez de Castro en el que éste, escueto, narra el abandono del hogar familiar (en Cisneros) de los hijos menores de Toribio, ${ }^{134}$ por no sufrir el duro carácter de su hermano mayor: Alvarus \& Alphonsus, duro Garsiae fratri ingenio cedentes, Campensi regione relicta, in transmontana sese contulerunt. Robles amplía un tanto esta información diciendo que, por desabrimientos y disgustos que tuvo con...su hermano mayor, que es el que tenía la casa y mayorazgo de su padre, se fue a estudiar a Salamanca, y yendo de vacaciones a Tordelaguna conoció allí a Marina de la Torre con la que luego casó. ${ }^{135}$

Lo coincidente en ambas versiones es que de manera implícita se está dando por sentado que el abandono de Alfonso Jiménez de su hogar se produjo después de la muerte de su padre, cuando su hermano mayor tenía la casa y mayorazgo. Y como su matrimonio se produjo después de dicho abandono, éste no podría haber sido anterior, sino incluso algo posterior a la fecha de la batalla de Olmedo, es decir, no antes de 1446. Lo que implica que el primogénito de ese matrimonio no podría haber nacido sino en 1447 o, a lo sumo, a fines de 1446.

Quintanilla coincide en la versión de Robles respecto a cómo conoció a su futura mujer, pero no menciona la ruptura familiar.

El indicio es serio, sin duda, pero hay que tomarlo con reserva. No hay seguridad absoluta en el dato de la muerte del abuelo del cardenal en la batalla de Olmedo, y quien lo $\mathrm{da}$, no recoge en cambio el de la ruptura entre los hermanos.

Pero en todo caso, la versión de Quintanilla es indicativa de que D. Toribio habría nacido entre 1395-1400, no siendo demasiado viejo para poder luchar todavía en la batalla de Olmedo. De su matrimonio con María de Bayona dejó tres hijos, siendo el mayor D. García, el segundo, Alvar y el tercero, Alfonso, el padre del cardenal. El orden de estos hijos, como ya hemos visto, lo da expresamente Robles, antes que Quintanilla y de manera implícita consta en Gómez de Castro. El padre del cardenal no pudo nacer, según eso, antes de 1420 y probablemente naciera después, lo que impediría que el cardenal naciera en 1436. La noticia que da Quintanilla de los estudios de D. Alfonso en Salamanca, ${ }^{136}$ según la cual se graduó de bachiller en cánones, impedirían que el matrimonio de éste (y el subsiguiente nacimiento del futuro cardenal) se llevara a cabo en su extrema juventud, por lo que, incluso fechando tempranamente el nacimiento de D. Alfonso (ca.1420), el nacimiento de su primogénito habría tenido lugar más cerca de 1445 que de 1440. Pero como esa noticia es dudosa, la tomamos en cuenta con reservas. ${ }^{137}$

En cualquiera de los casos, la noticia de la muerte del abuelo del cardenal en la batalla de Olmedo es un obstáculo para aceptar la fecha tradicional de nacimiento del cardenal. Podemos dudar de su exactitud, pero entonces hay que admitir que Quintanilla, al darla junto a la dicha fecha de nacimiento, incurre en contradicción.

\footnotetext{
134 Gómez de Casto, A. 1569: f. 1 v.

135 Robles, E. 1604: 5.

136 Ibídem, 23.

137 Para García Oro. Refrendada por Meseguer, J. 1974: 287-88
}

Una segunda fecha relativamente bien establecida nos hace examinar al hermano mayor del padre del cardenal, García Jiménez de Cisneros y a su descendencia. Que era el hermano mayor de su padre está bien establecido. Hay cierta discrepancia (ya lo hemos visto) entre sus biógrafos sobre cuántos hijos tuvo y el orden de los mismos. Gómez de Castro dice que fue mayor su hija María, mientras que Robles cree que lo fue García, el futuro abad benedictino. Quintanilla mantiene esta postura, pero amplía el número de hijas a tres más, de una de las cuales (Isabel) dice que es fruto de un segundo matrimonio del padre. García Oro acepta este número de hijas, sin precisar el orden de filiación.

Todo esto tiene importancia porque conocemos con bastante seguridad la fecha de nacimiento del primo hermano del cardenal, el monje benedictino García de Cisneros. Según la biografía del mismo por Dom García M. Colombás, ${ }^{138}$ que cita al primer biógrafo de García Jiménez de Cisneros, éste nació a fines de 1455 o en $1456 .{ }^{139}$ Y no sólo hay razones historiográficas para dar por buena esta fecha, sino que la biografía del futuro abad de Montserrat es congruente y está exenta de esos lapsos o vacíos que tiene la de su primo el cardenal. En efecto, García de Cisneros ingresó en la Orden de San Benito en 1475, esto es, con apenas 20 años, y desde entonces desarrolló en su seno toda su carrera.

Lo menos que podemos decir es que la diferencia de edad entre primos es sorprendente, sobre todo si se tiene en cuenta que se trata del hijo del hermano mayor de su padre. Cabría que, por razones que ignoramos, hubiera entre ellos alguna diferencia de edad, pero una diferencia de veinte años parece injustificada y coloca al abad benedictino en una generación posterior a la del cardenal. Así, no es extraño que historiadores antiguos, como, por ejemplo, Argaiz, ${ }^{140}$ hayan pensado que el abad era sobrino del cardenal. Lo que resulta extraño es que los historiadores modernos, conocedores del verdadero parentesco, no se hayan preguntado por la causa de esta diferencia de edades.

Y sólo hay dos explicaciones para esta diferencia. Una es que García fuera hijo del segundo matrimonio de su padre. Pero esto ni lo dicen ni lo dan a entender los biógrafos, e incluso dos de ellos (Robles y Quintanilla) afirman que fue el primogénito. La otra, que es la que nos parece más lógica, es que la fecha de nacimiento del cardenal esté antedatada.

Una tercera serie de fechas relativamente bien establecidas abona esta tesis. Nos referimos a las fechas de muerte de la generación anterior al cardenal.

Según el citado Colombás, ${ }^{141}$ García Jiménez de Cisneros, el hermano mayor del padre del cardenal, vivía aún en 1482. La versión tradicional que fechaba la muerte del padre del cardenal en 1465, quedó desmentida tras la publicación de un artículo de Juan Meseguer en 1974, basado en las inéditas Memorias de Tordelaguna (1668) de Quintanilla,

138 Colombás, G. M. 1955. Un reformador benedictino en tiempo de los Reyes Católicos: García Jiménez de Cisneros, abad de Montserrat: 1. Abadía de Montserrat. Scripta et Documenta, 5.

139 Jerónimo Lloret (ca.1500-71).

140 Argaiz, G. 1677. La Perla de Cataluña: Historia de Nuestra Señora de Monserrate. 114. Madrid, Impr. de Andrés García de la Iglesia.

141 Colombás, G. M. 1955: 13 n. 42. 
que fecha exactamente su muerte el 3 de junio de $1488 .{ }^{142}$ También consta documentalmente que su tío Álvar vivía aún en $1495 .{ }^{143}$ La muerte de la madre del cardenal, según las citadas Memorias de Tordelaguna de Quintanilla, en 1490, no rompe esta coherencia cronológica.

Esto es congruente con las fechas estimativas de nacimiento que más arriba hemos dado de esta generación, en torno a 1420-25, y con la idea de que la fecha de nacimiento del cardenal está antedatada, ya que implica fechas de nacimiento de la generación siguiente posteriores a 1440, y, más probablemente, a 1445. El nacimiento de García Jiménez en 1455-56 es compatible con este cálculo, aunque sugiere también su carácter conservador.

El siguiente rango de fechas se refiere a los hermanos del cardenal: Ignoramos las fechas de su nacimiento, pero sí conocemos algunas fechas de su vida con bastante aproximación.

Respecto de Juan Jiménez de Cisneros conocemos la fecha de su matrimonio, que fue en el otoño de 1497, según García Oro. ${ }^{144}$ Vallejo da $1496,{ }^{145}$ si bien el editor del Memorial, Antonio de la Torre, dice en nota al pie que el manuscrito está borroso en ese punto y no es seguro el año. La fecha aproximada del matrimonio viene ratificada por lo que sabemos de la fecha de nacimiento de sus hijos. De una, Juana, dice Robles que tenía poco más de 11 años cuando (en 1511) se negociaba su matrimonio con el conde de Coruña, ${ }^{146}$ y García Oro confirma que nació en $1499 .{ }^{147}$ De otro, Benito, dice García Oro que nació en $1502 .{ }^{148}$ Y aunque no sabemos tan aproximadamente la fecha de nacimiento de su tercera sobrina, María, es obvio que debió nacer también ca. 1500, porque su nieto mayor (el futuro cardenal Zapata) nació en 1550. Luego podemos dar por bien establecida dicha fecha de matrimonio.

Aunque sabemos que la esposa de Juan, Leonor de Luján, era muy joven al casarse, parece innegable que el hermano del cardenal debía ser bastante mayor. Ahora bien, ¿cuánto? Si aceptamos la versión tradicional habría debido nacer hacia 1440-45, como tarde. Así, tendría más de 50 años al casarse, edad no imposible, pero poco verosímil. En cambio, si situamos la fecha de su nacimiento en torno a la que se da de su primo García (ca.1455) su edad al casarse, con ser elevada, parece más probable.

La fecha de muerte de Juan Jiménez (1514), poco relevante para nuestra investigación, es sin embargo compatible con su nacimiento ca. 1455. Su primo García, por ejemplo, murió en 1510.

Tampoco del otro hermano, Bernardino, que fue fraile franciscano, sabemos la fecha de nacimiento. Pero sabemos que vivía aún en fecha tardía, aunque desconozcamos la fecha exacta de su muerte. Gómez de Castro, que nació en 1515 , dice haberlo conocido siendo niño, en su casi extrema

142 Vid. n. 92.

143 García Oro, J. 2002: 264

144 García Oro, J. 1992: I, 100.

145 Vallejo, J. 1913: 20.

146 Robles, E. 1604:.164.

147 García Oro, J. 1992: I, 100.

148 Ídem. En García Oro, J. 2002: 272, la afirmación es sólo aproximada: ca. 1502. senectud. ${ }^{149}$ Podemos fechar el recuerdo de Gómez de Castro en una fecha intermedia entre 1525-30, y aunque la expresión del autor es algo vaga, podría tener por entonces alrededor de 65 años. Eso situaría su nacimiento entre 1460-65. Bernardino murió en la década de 1530, según García Oro, ${ }^{150}$ por lo que un nacimiento anterior a 1450 puede descartarse con toda probabilidad, y hace bastante probable que naciera varios años después de 1455, en torno a 1460.

En suma, de la revisión de la cronología de su familia resulta como verosímil que su padre naciera hacia 1425 , que no se casara antes de 1445 , que sus hermanos nacieran entre $1450-60$ y consta que su primo hermano nació en 1456 . Por el contrario, para sostener la fecha de nacimiento del cardenal en 1436 habría que cuestionar la noticia de que su abuelo murió en la batalla de Olmedo (que da Quintanilla), o la de que su padre abandonó Cisneros por no sufrir a su hermano mayor (que dan Gómez de Castro y Robles). Además, habría que creer que todos los integrantes de la generación anterior fueron excepcionalmente longevos, que su hermano se casó a una edad inusualmente tardía, y aun así persistiría el enigma de por qué el hijo de su tío mayor era veinte años menor que él. La cronología que damos, además, es compatible con la documentación que poseemos sobre sus padres en Torrelaguna que se remonta sólo a la década de 1450, pese a lo cual García Oro sostiene que su padre se estableció en Torrelaguna a principios de la década de $1430,{ }^{151}$ afirmación que no parece tener otra base que la creencia tradicional de que el cardenal nació en 1436.

\section{CRONOLOGÍA DE CONTEXTO}

Llamamos así a la cronología que rodea la vida del cardenal a lo largo de su vida, en la medida en que ésta nos permite deducir su situación relativa, esto es, su edad. Hay aquí pocas fechas categóricas, y las que hay no son suficientes para determinar de manera segura la edad del cardenal. Además, hay otros hechos indicativos de incongruencia o inverosimilitud cronológica, que abonan la tesis que sostenemos.

Empezamos con las fechas categóricas, que son dos, y corresponden a sendos documentos pontificios: la bula de provisión del arciprestazgo de Uceda y el breve de León $\mathrm{X}$ que cita Quintanilla, al que ya nos hemos referido.

La bula de provisión es del 22 de enero de 1471. Lo categórico no es que conozcamos de manera fehaciente su fecha, sino que conste en la misma que Gonzalo Jiménez (Gundisalvus de Tordelaguna) era ya bachiller en decretos (baccalaurius in decretis). Esto tiene relevancia para determinar su edad mínima en esa fecha, pues habitualmente el título de bachiller se obtenía en tres o cuatro años, a partir de unos estudios iniciados a los 15 o 16. De modo que si en enero de 1471 ya era bachiller, eso significaba que el título, como tarde lo había obtenido en 1470, y que Cisneros tenía

149 Gómez de Castro, A. 1569: I fo. 16 v.: Hunc ego Bernardinum extremam penè senectam agentem puer olim Compluti vidi.

150 García Oro, J. 2002: 271.

151 García Oro, J, 1992: I, 9. 
no menos de $18-20$ años en 1470 , esto es, que no podía haber nacido más tarde de 1450-52. Si admitimos como verosímil la afirmación de Quintanilla (que García Oro mantiene) de que continuó dos o tres años más en Salamanca tras obtener su título, podríamos adelantar este nacimiento a no más tarde de 1447-50. Naturalmente, nada impide que hubiera un lapso de tiempo mayor entre la obtención del título y la provisión del arciprestazgo. Pero que ese lapso fuera de más de 10 años es lo que parece inverosímil, sobre todo si se cuestiona, como lo hace la historiografía moderna, una larga estancia de Cisneros en Roma.

La segunda fecha categórica es la del breve de 31 de mayo de 1517. Ya hemos dicho con qué facilidad solventa Quintanilla el tenor literal del breve (qui septuagessimum \& ultra tuae aetatis annum agis) diciendo que tener ochenta años es tener más que setenta. Parece conveniente aclarar, con carácter previo, que ese breve que, según Quintanilla, ${ }^{152}$ queda en nuestro Archivo Original y se copió y compuso con Autoridad Ordinaria en el proceso para su Beatificación, coincide en su dicción con el que recoge Waddingen sus Annales. ${ }^{153}$

Esto lo decimos porque aunque Quintanilla traduce correctamente el breve (Sabe su Santidad que tenía más de setenta años) no es el caso de otros autores. Señalemos que, frente a la correcta traducción de la versión española de la obra de Fléchier ${ }^{154}$ (passando ya de los setenta años de edad), ${ }^{155}$ la edición original francesa de la biografía de éste dauna versión francamente abusiva (encore que vous soyiez âgé de près de 80 ans), ${ }^{156}$ al igual que lo hace Alcolea (Hemos sabido que tú, pasando ya mucho más de los 70 años de edad.... $)^{157}$.

Detengámonos un poco en esta cuestión, que es interesante. Tanto Quintanilla como Fléchier y Alcolea parten sin duda de la sincera convicción de saber que el cardenal tenía ochenta años. Incluso Quintanilla dice que ya tenía cumplidos ochenta, como se verá después. ${ }^{158}$ Pero después sólo dice que había cumplido los 81 al morir, sin justificarlo en manera alguna.

Pero Fléchier y Alcolea van más allá, haciendo decir al texto del breve lo que éste no dice, a saber que tenía cerca de 80 años (Fléchier) o que tenía muchos más de 70 (Alcolea). Esto, a sensu contrario, es significativo de la verdadera dicción del breve: Cisneros tenía, según él, más de 70 años, pero ni estaba cerca de los 80 , ni tenía muchos más de 70.

Aún más, el sentido original de septuagessimum referido a su edad (tuae aetatis) quiere decir en el cómputo antiguo que el aludido estaba en su septuagésimo año de vida, es decir, que había cumplido los 69 años, pero no los 70. El ultra que se añade indicaría, por tanto, que se habían cumplido ya, al menos, los 70 , pero como hemos visto, no mucho más.

\footnotetext{
152 Quintanilla, P. 1653: L. IV, 279.

153 Wadding, L. 1736: XVI, 37.

154 Fléchier, E. 1696: 457.

155 Wadding, L. 1736: XVI, 37

156 Fléchier, E. 1693: II, 350.

157 Alcolea, N.A. 1777: 115.

158 Quintanilla, P. 1653: L. IV, 280.
}

De modo que el breve indicaría que Cisneros tenía poco más de 70 años a fines de mayo de 1517, por lo que podría haber nacido en 1446 o poco antes, o incluso en los primeros meses de 1447.

Claro, esto sería así si pudiésemos dar por cierto que León X sabía con suficiente exactitud la edad del cardenal. Esto es poco probable. Sin embargo, no parece inverosímil que tuviera una idea aproximada. De modo que podríamos afirmar que, grosso modo, el Papa sabía que tenía alrededor de los 70 años, pudiéndose equivocar en un margen de uno o dos años, arriba o abajo.

La importancia de este breve radica en que es el único documento contemporáneo del cardenal que se refiere a su edad. Hay que esperar cincuenta años a que Gómez de Castro mencione (de manera igualmente aproximada) la edad del cardenal al morir. $Y$ aunque no se le puede dar un valor fehaciente absoluto, es indiscutible que tiene mayor valor, siquiera sea como opinión cualificada, que la de historiadores posteriores como Gómez de Castro, Robles o Quintanilla, que escriben entre medio siglo y siglo y medio después.

Parece asombroso que los historiadores antiguos, pero sobre todo los modernos, no hayan reparado en la importancia de este breve. Específicamente, García Oro, que menciona abundantemente a Quintanilla, no dice una palabra respecto de este breve y, sin embargo, menciona diversos breves de dicho Papa dirigidos a Cisneros en 1514..$^{159}$

Pero es que además, la versión más literal del breve es perfectamente congruente con cuanto hemos venido diciendo, que sugiere, por razones diferentes, la misma conclusión: que Cisneros nació en una fecha que cabe situar entre 1445 y 1450 .

Otros hechos de la vida de Cisneros aportan indicios que permiten concluir un resultado similar, esto es, el retraso de su fecha de nacimiento entre diez y quince años.

De los datos que tenemos sobre su educación inicial, contradictorios, no parece posible deducir nada. De sus estudios de gramática, en cambio, podríamos deducir algo si aceptáramos la versión inicial que daba García Oro en el artículo biográfico del Diccionario de Historia Eclesiástica de España de que estudió en el Estudio Viejo anejo al convento de los franciscanos. Porque, en efecto, el convento franciscano de Santa María de Jesús no comenzó a construirse antes de 1453, y si Cisneros (según dice Quintanilla) empezó a estudiar en Alcalá a los diez años, no habría nacido antes de 1443, y seguramente algo después.

Pero Vallejo no menciona que estudiara en Alcalá, Gómez de Castro lo da en unos términos que parecen excluir al Estudio (ad Grammaticae preceptores Compluiu), ${ }^{160}$ y el propio García Oro relativiza su afirmación de 1972 en su obra principal, diciendo sólo que es posible que acudiera a Alcalá. ${ }^{161} \mathrm{Y}$ en sus versiones posteriores parece inclinarse porque estudiara en su casa, ${ }^{162}$ o que los realizara en la

\footnotetext{
159 García Oro, J. 1992: I, 286.

160 Gomez de Castro, A. 1569: fo. 2 r.

161 García Oro, J. 1992: I, 21.
}

162 García Oro, J. 2002: 28. 
misma Salamanca. ${ }^{163}$ Por todo ello, no parece posible sacar conclusiones al respecto.

Respecto de su estancia en Salamanca, parece posible aceptar la versión de Quintanilla, en cuanto a la edad en que cursó allí sus estudios, y no hay ninguna inverosimilitud en pensar que una vez obtenido el título de bachiller prolongó su estancia allí por dos o tres años. Ahora bien, la única noticia concreta que tenemos de sus estudios, aparte de su título de decretos, es la de que estudió Filosofía y Teología con el maestro Roa. A partir de Gómez de Castro, todos sus biógrafos lo mencionan, hasta llegar a García Oro, que mantiene un silencio absoluto al respecto.

El silencio es comprensible, porque dicha noticia plantea nuevamente una incongruencia cronológica.

$Y$ es que, a diferencia de Cisneros, de cuya estancia en Salamanca no hay registro alguno, la estancia de Roa en Salamanca está relativamente bien documentada y se sabe que estudió allí al menos desde 1466, que fue regente de una cátedra de Lógica en 1469, cátedra que obtuvo en 1473. En la década siguiente, Roa sería catedrático de Teología.

La incompatibilidad de estas fechas con las de la biografía tradicional de Cisneros, según la cual habría estudiado en Salamanca entre 1450-59, es absoluta.

Las fechas que hemos dado del magisterio de Roa vienen establecidas por Esperabé, ${ }^{164}$ que menciona la fecha en que fue regente y la de obtención de la cátedra. La fecha de esta última la confirma Beltrán de Heredia, ${ }^{165}$ y más modernamente Labajos. ${ }^{166}$ Son, pues, bastante seguras, y admitir que Cisneros asistió a clases de Filosofía (y aún más de Teología) de Roa es incompatible con la bula de provisión del arciprestazgo de Uceda, pues los estudios de Cisneros se habrían prolongado más allá de 1471. No es de extrañar que Beltrán de Heredia llegue a la conclusión de que la afirmación de la versión tradicional falla por incompatibilidad cronológica. ${ }^{167}$

Ahora bien, en su obra ya citada, ${ }^{168}$ Erika Dolphin analiza esta cuestión con mayor detenimiento, fijándose en los términos con que describe Gómez de Castro esta relación: scholis operam dare magistro Roensi celeberrimo tunc harum doctrinarum professori, ${ }^{169}$ que no es, como dicen sus seguidores, que oyo Philosophia y Theologia del maestro Roa. ${ }^{170}$ Según Dolphin (que utiliza la traducción de Oroz), lo que dice Gómez de Castro es que ayudaba, en las disputas

163 García Oro, J. 2005: 36.

164 Esperabé de Arteaga, E. 1917: Historia pragmática e interna de la Universidad de Salamanca. II,. 247 y 274. Salamanca, Imp. Francisco Núñez Izquierdo.

165 Beltrán de Heredia, V. 2001. Cartulario de la Universidad de Salamanca. II, 239. Salamanca, eds. Universidad.

166 Labajos Alonso, J. 2012: "Pedro de Osma y Fernando de Roa: significación histórica" en C Flórez Miguel/ M.Hernández Marcos/ R.Albares Albares (eds): La primera escuela de Salamanca (1406-1516), 146. Salamanca. Eds. Universidad.

167 Beltrán de Heredia, V. 1959. "Vicisitudes de la filosofía aristotélica en Alcalá" en "IV Semana de Filosofía” CSIC, 215-26,. en Miscelánea Beltrán de Heredia IV, 1973. Salamanca, Biblioteca de teólogos españoles p. 160.

168 Dolphin, E. 2008. Op.cit.

169 Gómez de Castro, A. 1569: I fo. 2.

170 Robles, E. 1604:.37. públicas de filosofía y teología, al maestro Roa, profesor celebérrimo a la sazón en estas disciplinas. ${ }^{171}$

Que a la sazón Roa no era un profesor celebérrimo de Filosofía, y menos aún de Teología, es algo indiscutible, pero esto puede ser un mero anacronismo. Aun así, la frase, para Dolphin es compatible con que ambos (Cisneros y Roa) fueran compañeros de estudios y participaran en disputas públicas sobre temas filosóficos y teológicos, en las que Cisneros (que no era estudiante de esas materias) intervenía para ayudar a Roa. Y eso es lo que afirma como probable Dolphin: it is most likely that they were fellow students. ${ }^{172}$ Aún va más lejos la autora, añadiendo: ${ }^{173}$ They were probably quite close in age. ${ }^{174}$

Y ¿qué edad tenía Roa? La autora, citando a Castillo Vegas, ${ }^{175}$ dice que nació algo antes de 1448. También sabemos que Roa aparece como estudiante en Salamanca en $1466,{ }^{176}$ aunque es posible que estuviera ya antes. De modo que, si es cierto que Cisneros tuvo relación con Roa, ésta no pudo ser de alumno, sino más probablemente de compañero de estudios. Esto significa a su vez dos cosas: Que Cisneros tenía una edad similar a la de Roa (esto es, que habría nacido en torno a 1448) y que estudiaba aún en Salamanca ca.1466.

Ambos requisitos son incompatibles con la fecha de nacimiento tradicional (1436) y, en cambio, apuntan a una fecha muy similar a la que otros indicios independientes señalan como la de nacimiento de Cisneros, esto es, en torno a 1445-50.

Cabe desde luego solventar la cuestión negando toda verosimilitud a la afirmación de Gómez de Castro. Pero esta actitud, en sí misma legítima, empieza a ser demasiado repetida, es decir, hay que suprimir muchas cosas de las que dicen sus biógrafos tradicionales, con el único objeto de mantener algo que igualmente procede de ellos, esto es, que nació en 1436. Además, aunque el episodio de Roa no tenga, por sí mismo, gran significación, lo recogen tres de sus cuatro primeros biógrafos, y entre ellos Gómez de Castro, que aunque no pudo conocer a Roa, tal vez conoció a gente que fue alumna suya, pues pertenecían a un mismo mundo académico, por lo que su noticia tiene especial valor.

El siguiente hecho de la vida de Cisneros que resulta relevante es el de su cargo de gobernador o corregidor de Uceda. Digamos ante todo que es discutible cuál fuera ese cargo, que sólo menciona Vallejo y algún autor posterior como Alcolea, con denominación distinta de la que le da García Oro. Y cabría plantearse si no sería un mero lugarteniente del corregidor titular. Pero esto son especulaciones, pues no tenemos ninguna prueba que lo acredite.

Es precisamente la ausencia de todo documento que lo acredite lo que nos parece significativo, y no necesariamente

171 Gómez de Castro, A. 1984: 32.

172 Dolphin, E. 2008: 16.

173 Ídem.

174 Sin embargo, la autora no va más allá de esta afirmación y no cuestiona la fecha tradicional de nacimiento de Cisneros.

175 Política y clases medias: el siglo XV y el maestro salmantino Fernando de Roa (Universidad de Valladolid. 1987).

176 Díaz Díaz, G. 1998. Hombres y documentos de la Filosofía española VI, 806. Madrid, CSIC. 
de que no lo ejerciera, sino en cuanto favorece la hipótesis de un desempeño breve del cargo, y descarta, verosímilmente, un largo ejercicio del mismo. El silencio de la mayoría de los biógrafos apoya esta hipótesis. Por ello no compartimos la sugestión implícita que, en términos vagos, ${ }^{177}$ hace García Oro, de que en tal desempeño habría pasado gran parte de la larga década que transcurrió entre el final de sus estudios en Salamanca y su nombramiento como arcipreste de Uceda.

En cuanto el viaje a Roma, una vez abandonada la idea de una prolongada estancia, carece de importancia cronológica. Fernández de Retana aún trata de justificarlo por el tenor literal de la bula, ${ }^{178}$ que testimoniaría del conocimiento personal que el Papa (Paulo II) tenía de Cisneros, pero no nos parece que ésta sea una conclusión necesaria, $y$, en todo caso, no exigiría una estancia prolongada. Que el viaje se realizara, como sugiere García Oro en $1470,{ }^{179}$ o, como dice Vallejo, después de su provisión es también irrelevante a nuestros efectos.

Los hechos posteriores no son susceptibles de determinar una edad concreta, aunque sí sugieren que la edad que se le atribuye tradicionalmente es muy elevada. Así, el ingreso en el otoño de 1484 de Cisneros en la O.F.M. resulta menos probable en alguien que fuera, como lo describe García Oro, ${ }^{180}$ un hombre maduro que avanzaba por el quinto decenio de su vida, que si estuviera entonces por los 35 años.

Del mismo modo, los sucesivos cargos que desempeña los asume con una edad que hay que calificar objetivamente de avanzada para la época. Algún historiador lo ha señalado así. Por ejemplo, Fernández Álvarez comenta de pasada, al hablar de su nombramiento como confesor de la reina, que tenía entonces 56 años, una edad avanzada para la época. ${ }^{181}$

En el mismo sentido hay un curioso indicio relativo a su nombramiento como arzobispo de Toledo. Cuentan los historiadores (entre ellos Gómez de Castro y Quintanilla, aunque poniéndolo en duda) que el primer candidato de la reina Isabel para el arzobispado fue Pedro de Oropesa, y que al rehusar éste, lo ofreció a Cisneros. Oropesa nació ca. $1455,{ }^{182}$ y esto parece indicativo de una edad (en torno a los 40 años) que se consideraba apropiada para el cargo. Sin pretender sacar del episodio otra conclusión, parece obvio que la edad (58 años) que según la versión tradicional tenía Cisneros al ser nombrado arzobispo resulta comparativamente muy avanzada.

En fin, la energía de que dio prueba en el cargo, su participación en la expedición a Orán a una edad poco verosímil en la época (73 años), o su nombramiento como regente con 80 años son indicios todos ellos de una edad demasiado avanzada, y hasta menos probable que una edad diez

177 García Oro, J. 1992: I, 28: en una fecha desconocida de estos años.

178 Fernández de Retana, L. 1929: I, 61.

179 García Oro, J. 1992: I, p, 30. De nuevo, García Oro, J. 2005: 42.

180 García Oro, J. 2002: 45.

181 Fernández Álvarez, M. 2011. Isabel la Católica..525. Madrid, Espasa.

182 Robles, E, 1604: 74, habla sin embargo de su mucha edad y le Ilama anciano y venerable. o quince años inferior. El que su propia muerte, en plena jornada, suscitara rumores, de los que se hacen eco, aunque sea para desmentirlos, el propio García Oro, ${ }^{183}$ o Alcolea, ${ }^{184}$ de envenenamiento, parece compadecerse mal con la edad octogenaria que se le atribuye.

\section{RESUMEN Y CONTROVERSIA}

Todo lo antedicho no demuestra nada de manera concluyente. Incluso, si se analiza punto por punto, cabe encontrar razones para desmentir cada uno de ellos, con igual falta de rotundidad, dicho sea de paso. Se puede, en efecto, negar la exactitud de Quintanilla al decir que el abuelo del cardenal murió en la batalla de Olmedo, se puede desmentir la versión de Gómez de Castro (y de Robles) sobre la marcha del padre del cardenal de su hogar familiar, se puede recurrir a explicaciones no por poco probables imposibles respecto a la longevidad de todos los integrantes de la generación anterior, o desdeñar las incongruencias cronológicas que presentan la fecha de nacimiento del abad García de Cisneros o la de la tardía boda del hermano del cardenal. Se puede considerar legendaria la mención de Gómez de Castro (y de Robles y de Quintanilla) del maestro Roa y salir del paso con una explicación insuficiente del tenor literal del breve de 1517 de León $\mathrm{X}$, pero en primer lugar hay que negar o eludir demasiadas cosas, y en segundo lugar, aún así, subsiste el interrogante respecto de lo que hizo Cisneros en la década comprendida entre 1459 y 1470.

Las explicaciones tradicionales reducían un tanto el problema atribuyéndole una estancia de seis años en Roma (de la que no hay rastro fehaciente). Pero tanto la fecha como el motivo presunto de su vuelta en 1465 se han visto desmentidos por la confirmación moderna de que su padre murió 23 años después, y no hay razón para pensar que, si hubo tal viaje, fuera de mucha duración. Aun así, en su biografía tradicional quedaban años por justificar, y la versión de Quintanilla de que se dedicara a administrar su hacienda y otros beneficios (innominados) que se trajo de Roma resultaba muy insatisfactoria. ${ }^{185}$

El nombramiento como gobernador o corregidor de Uceda que da Vallejo es mucho más verosímil, ${ }^{186}$ tanto más cuanto que convertía a Cisneros en testigo privilegiado de la falta del arcipreste García de Guaza, que le permitiría denunciarla con conocimiento de causa y, eventualmente, sustituirlo en el cargo.

A esta versión se acoge precisamente García Oro para justificar el largo periodo comprendido entre el final de sus estudios en Salamanca (ca. 1459) y su nombramiento como arcipreste en 1471. Ahora bien, no hay datos que apoyen tan largo desempeño, y su ausencia, junto al silencio de sus biógrafos iniciales (con la única excepción de Vallejo) parece más bien indicativa de un desempeño corto del cargo, que

183 García Oro, J. 1972. “Jiménez de Cisneros, Francisco” en Q. Aldea (Dir.). Diccionario de Historia Eclesiástica de España. Madrid. CSIC. Vol. II, 1239.

184 Alcolea, N.A. 1777: 122.

185 Quintanilla, P. 1653: 9.

186 Vallejo, J. 1913: 2-3. 
de otro modo habría dejado un mayor rastro documental o en la tradición oral.

Pero en la postura, por lo demás vaga e imprecisa, de García Oro, parece prevalecer el respeto a la fecha tradicional de nacimiento y eso hace preciso llenar con ese cargo un lapso temporal a todas luces excesivo.

Y ¿ipor qué hay que dar por cierto que naciera en 1436 ? García Oro, ya lo hemos visto, mantiene que dicha fecha de nacimiento es imposible de comprobar, que sólo consta por Quintanilla. Pero que se acomoda bien con otras noticias seguras sobre su edad en el momento de realizar algunas de sus empresas y, sobre todo, a la hora de la muerte. ${ }^{187}$

Estas afirmaciones precisan algún comentario. Siendo cierto, en primer lugar, que es Quintanilla el primero que habla de 1436, no lo es menos que éste explicita algo que está implícito ya en Robles, cuando dice que murió de edad de ochenta y un años. ${ }^{188} \mathrm{Y}$ aunque de manera sólo aproximada, lo está igualmente en Gómez de Castro cuando diceque al morir su edad era aproximadamente de 80 años. ${ }^{189}$ Por tanto, Quintanilla sólo saca a la luz la cifra del año en que debía haber nacido para tener cumplidos los 81 años en noviembre de 1517. Ahora bien, si en Gómez de Castro hay una prudente afirmación del carácter aproximado de la edad que tenía al morir, a partir de Robles se observa una cierta seguridad cuya causa ignoramos.

Tal vez estas sean las que llama García Oro noticias seguras sobre su edad. Porque Robles, como hemos visto, empieza afirmando que tenía 58 años al ser nombrado arzobispo, y del periodo del desempeño del cargo (22 años y 8 meses) parece deducir que estaba en los 81 al morir. No negamos que Robles estuviera seguro de lo que decía. Pero no podemos compartir su seguridad, pues no hay ninguna constancia documental de ello. Del mismo modo, la ligereza con que Quintanilla rebate (o malinterpreta) el breve de León $X$ se basa en una seguridad que aplaza justificarnos (como se verá después) sin que luego se vea sino una reiteración de que tenía cumplidos los 81 años. Y como en esa época no había partidas de bautismo y se puede descartar que hubiera un documento fehaciente que probara su nacimiento en 1436, dudamos mucho que la seguridad de Quintanilla y de Robles tuviera otra base que una tradición que en su época estaba ya muy arraigada. El propio García Oro reconoce, como hemos visto, esa imposibilidad de comprobar la fecha de manera fehaciente. Pese a lo cual, trata de mantenerla con razones insuficientes.

La única razón para admitir esa fecha de nacimiento es, por tanto, su carácter tradicional, una tradición relativamente temprana que se documenta por primera vez en Gómez de Castro, unos 50 años después de su muerte, pero que seguramente se inició antes, incluso, probablemente, en vida de Cisneros. Es muy posible, en efecto que sus contemporáneos lo creyeran octogenario al morir, aunque seguramente con eso aludirían a su edad avanzada, bastante mayor que la media de entonces.

187 García Oro, J. 1992: I, p.18. Idéntica dicción en 2005: 34

188 Robles, E. 1604: 201.

189 Gómez de Castro, A. 1569: fo. 215: etatis verò circiter octogésimo.
Pero esa tradición, arraigada incluso, no puede sostenerse cuando, como hemos dicho, se producen incongruencias y contradicciones en la biografía del personaje y en la confrontación de su cronología con la de sus contemporáneos y familiares. Creemos haber demostrado que esto último es lo que sucede en el caso de Cisneros, en cuya biografía hay incongruencias y contradicciones que, si no son insalvables una a una, en su conjunto desmienten la versión tradicional, o al menos la hacen menos verosímil que otra que retrase su fecha de nacimiento entre diez y quince años.

\section{CRONOLOGía REVISADA DE LOS PRIMEROS AÑOS DEL CARDENAL JIMÉNEZ DE CISNEROS}

Una vez demostrada la insuficiencia de la tradición que fundamenta la fecha de nacimiento de Cisneros para salvar las numerosas contradicciones e incongruencias en que incurre su biografía, toca intentar determinar cuál sea la fecha más probable de nacimiento del cardenal, cosa que sólo podemos hacer con cierta aproximación.

Hemos hablado de entre diez o quince años después, y tal lapso temporal resulta del entrecruzamiento de varios elementos independientes. En primer lugar, la existencia de un periodo de tiempo en el que se desconoce qué pudiera estar haciendo Cisneros. Este periodo probablemente va de 1459 (fecha en que según la versión tradicional terminó sus estudios en Salamanca) hasta fines de 1470, ya que consta su nombramiento como arcipreste de Uceda en enero de 1471. El periodo se puede alargar dos o tres años más si no aceptamos que, tras obtener su título de bachiller, prolongara sus estudios en Salamanca, pero también se puede acortar un tanto (aunque no mucho) si aceptamos que fuera gobernador de Uceda con anterioridad. De ahí que el periodo resultante pueda oscilar entre los diez y los quince años.

Junto a eso, hay que tratar de fijar, con los datos que tenemos, las fechas de nacimiento más antigua y más reciente posibles de Cisneros.

Ya hemos dicho que la bula de provisión del arciprestazgo de Uceda testimonia que no podía haber nacido después de 1451-52, pues tenía que haber obtenido como tarde el grado de bachiller en 1470 , y lo probable es que hubiera nacido algo antes (entre 1447-50).

Por otro lado, si aceptamos (como dice Quintanilla) que su abuelo murió en la batalla de Olmedo y que (como se deduce de Gómez de Castro) el padre del futuro cardenal marchó a Torrelaguna después, apenas es posible que Cisneros naciera en 1446, y nunca antes, siendo más probable su nacimiento a partir de 1447.

En fin, si tomamos literalmente el breve de León $X$, Cisneros no podría haber nacido después de 1447, y aun es probable que naciera algo antes, pues no sería en la fecha del breve (31 de mayo de 1517) septuagenarius et ultra.

En fin, si aceptamos la opinión de Dolphin, Cisneros sería muy próximo en edad al maestro Roa, que nació algo antes de 1448.

Se observará que todos los elementos coinciden en situarse en torno al año 1447, pues esta fecha cumple con 
todos los requisitos, algunos de los cuales son hipotéticos, es decir, se basan en dar por ciertas algunas de las noticias contemporáneas u obrantes en su biografía, de las que no tenemos más constancia que la historiográfica.

Como toda fecha intermedia, la fecha indicada resulta poco satisfactoria cuando se la confronta con cada uno de los criterios utilizados. Así, la cronología de su familia parecería exigir una fecha más tardía de nacimiento. Que el cardenal fuera ocho o nueve años mayor que su primo el abad es cosa que sigue produciendo cierta perplejidad, y que sus hermanos nacieran verosímilmente en la primera mitad de la década de 1450 no es tampoco del todo acorde con otros datos de su vida. Pero no hay en ello imposibilidad alguna, sino mera insatisfacción.

Lo mismo ocurre con el breve de León $\mathrm{X}$, ya que si bien cumple con el tenor literal del mismo, hay que reconocer que sería más probable una fecha anterior, que reforzaría el ultra que se adiciona al septuagesimus.

Pese a ello y con el carácter aproximado con que cabe dar una fecha deducida, podemos afirmar que el nacimiento de Cisneros se produjo en torno a 1447, aunque parece posible que lo hiciera en algún otro año del intervalo 1445-1450.

De acuerdo con eso, ésta sería la cronología revisada de los primeros años de Cisneros:

1447: Nacimiento en Torrelaguna

ca. 1453: Estudios primarios en Roa o Torrelaguna

ca. 1457: Estudios de Gramática en Cuéllar y, tal vez, posteriormente (después de 1458) en Alcalá.

ca.1462: Estudios en Salamanca

ca. 1467: Bachiller en Cánones

ca. 1467-69/70: Permanencia en Salamanca. Contacto con Roa

ca.1469-70: Regreso a Torrelaguna. Corregidor de Uceda. 22-I-1471: Arcipreste de Uceda.

Como ya hemos dicho, los estudios primarios no afectan (ni son afectados) por la nueva cronología, y sólo la disparidad de las fuentes nos impide establecer dónde los hizo.
Parece lógico seguir en cuanto a los secundarios a Vallejo, que es el testigo más próximo, y por eso se da preferencia a Cuéllar. Pero es posible que el establecimiento en Alcalá del Estudio General en 1458 motivara su traslado allí después de esa fecha. La fecha de su bachillerato se da de acuerdo con la edad que según Quintanilla tenía en esa época, que es verosímil. El margen de contacto con Roa (alumno en Salamanca desde al menos 1466) le habría permitido tal vez incluso asistir a las clases de éste como regente de la cátedra de Lógica (desde 1469). El cargo de corregidor de Uceda habría sido de breve desempeño entre 1469/70 y 1471.

Esta cronología elimina (o reduce al mínimo) el margen de incertidumbre respecto de la vida del cardenal en sus primeros años. Se acomoda a lo que sabemos de la cronología de su familia y hace coincidir su edad con la que le atribuye el breve de León $\mathrm{X}$, es decir, subsana las incongruencias que se observan en la cronología de sus primeros años por una fecha tradicional de nacimiento antedatada.

\section{APÉNDICE: GENEALOGÍA RESUMIDA DE LOS JIMÉNEZ DE CISNEROS}

En el cuadro sucinto que acompaño, para mayor claridad, he dado las fechas que parecen contar como indubitadas (o muy aproximadas), poniendo en algún caso ca., por no constar fecha exacta. Doy con interrogantes las fechas de muerte del abuelo del cardenal, que no dan varios autores y no puede considerarse segura, así como la fecha que yo doy de nacimiento del propio cardenal, que sólo considero como una hipótesis por admitir. He numerado a los hermanos de cada generación por el orden de nacimiento y he omitido a las primas hermanas del cardenal por no ser relevantes a los efectos de este artículo. Del citado cuadro se desprende cierta congruencia generacional, esto es, los miembros de la generación de los padres del cardenal y los de la del propio cardenal tienen fechas de muerte congruentes, por lo que cabría pensar que sus fechas de nacimiento lo sean también.

GENEALOGÍA (RESUMIDA) DE LOS JIMÉNEZ DE CISNEROS

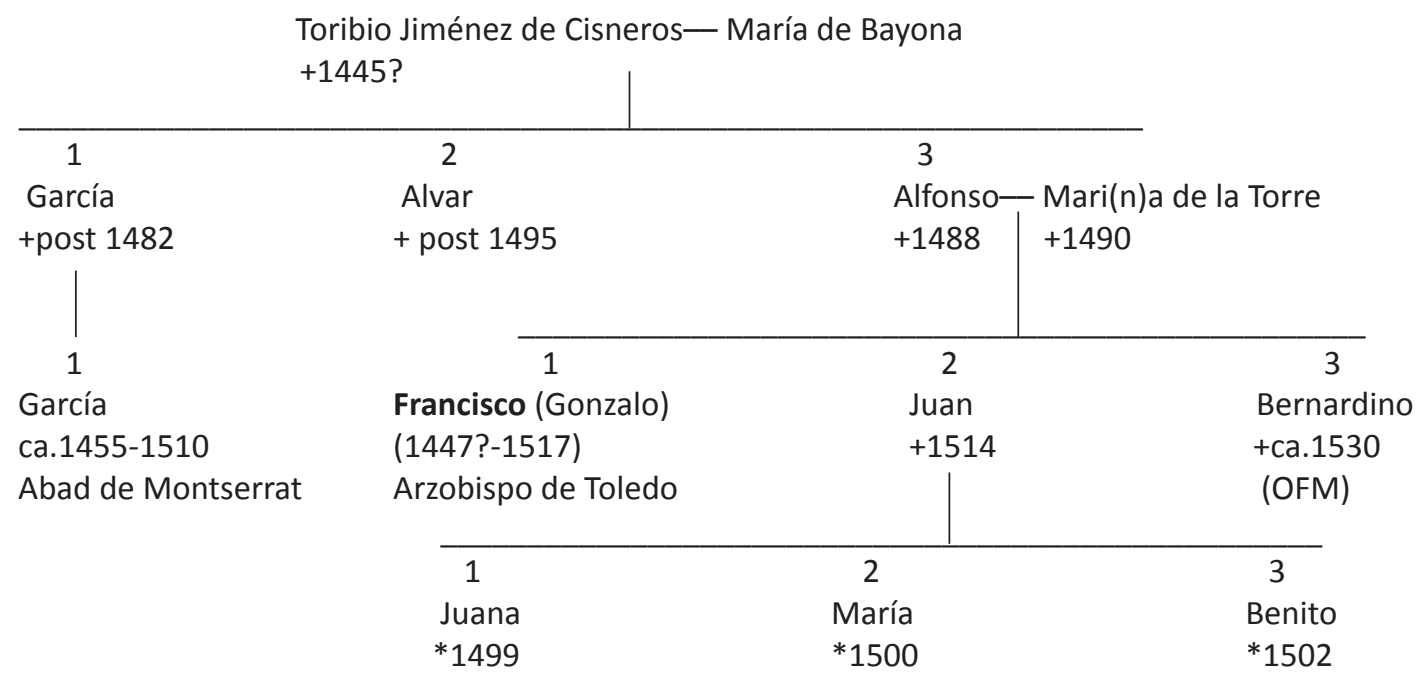




\section{BiBLIOGRAFÍA}

Alcolea, N.A. 1777. Seminario de nobles, taller de venerables y doctos, el Colegio Mayor de S. Pedro y S. Pablo, fundado en la Universidad de Alcalá de Henares para trece religiosos de todas las provincias Observantes de N. P. S. Francisco de estos Reynos por el Emmo. y Ven. Cardenal de España mi Señor, D. Fr. Francisco Cisneros, lustre de toda la religión seráfica, con su admirable vida. Madrid. Impr. de Manuel Martín.

Argaiz, G. 1677. La Perla de Cataluña: Historia de Nuestra Señora de Monserrate. Madrid, Impr. de Andrés García de la Iglesia.

Beltrán de Heredia, V. 2001. Cartulario de la Universidad de Salamanca (1218-1600). (6 vols.). Salamanca. Eds. Universidad.

Beltrán de Heredia, V. 1959. "Vicisitudes de la filosofía aristotélica en Alcalá" en "IV Semana de Filosofía" CSIC, pp. 215-26, recopilada en Miscelánea Beltrán de Heredia IV, 1973. Salamanca, Biblioteca de teólogos españoles.

Cedillo, J. L. de A., conde de. 1921. El cardenal Cisneros, gobernador del reino (2 vols.) Madrid. Real Academia de la Historia.

Ciaconius, A. 1677. Vitae et res gestae Pontificum Romanorum et S. R. E. Cardinalium ab initio nascentis Ecclesiae, usque ad Urbanum VIII (2 vols.) Roma. Philippi et Ant. De Rubeis.

Colombás, G.M. 1955. Un reformador benedictino en tiempo de los Reyes Católicos: García Jiménez de Cisneros, abad de Montserrat. Abadía de Montserrat. Scripta et Documenta, 5.

Dolphin, E. 2008. Archbishop Francisco Jiménez de Cisneros and the Decoration of the Chapter Room and Mozarabic Chapel in Toledo Cathedral Ann Arbor, Michigan. ProQuest.

Esperabé de Arteaga, E. 1917: Historia pragmática e interna de la Universidad de Salamanca. (2 vols). Salamanca. Impr. Francisco Núñez Izquierdo.

Fernández Álvarez, M. 2011. Isabel la Católica Madrid, Espasa.

Fernández del Pulgar, P. 1673: Vida y motivos de la común aclamación de santo del venerable siervo de Dios $D$. Fr. Francisco Ximenez de Cisneros... Madrid. Vda. de Melchor Alegre.

Fernández de Retana, L. 1929-30. Cisneros y su siglo (2 vols.). Madrid. Administración del Perpetuo Socorro.

Fléchier, E. 1693. Histoire du cardinal Ximènes (2 vols.) París, chez Jean Anisson.

Fléchier, E. 1696. Historia de el señor Cardenal Don. Francisco Xmenez de Cisneros (trad. de Miguel Franco de Villalba) Zaragoza. Pascual Bueno.

Forcella, V. 1869-79. Iscrizioni delle chiese e d'altri edificii di Roma dal Secolo xI fino ai giorni nostri. 13 vols, Roma. Tipografia delle Scienze Matematiche e Fisiche.
García, I. 1973. Quiñones, Francisco de los Ángeles, en Q. Aldea (Dir.), Diccionario de Historia Eclesiástica de España, vol. III, pp. 2037-2038. Madrid. CSIC.

García Oro, J. 1972 "Jiménez de Cisneros, Francisco" en Q. Aldea (Dir.). Diccionario de Historia Eclesiástica de España II: 1238-39 Madrid. CSIC.

García Oro, J. 1992 El cardenal Cismeros. Vida y empresas (2 vols.) Madrid, B.A.C.

García Oro, J. 2002. Cisneros. Barcelona. Ariel.

García Oro, J. 2005. Cisneros, un cardenal reformista en el trono de España (1436-1517). Madrid. La Esfera de los Libros.

García Oro, J. 2011: Jiménez de Cisneros, Francisco en G. Anes (Dir.) 804-809. Diccionario Biográfico Español, Madrid, Real Academia de la Historia, T. XXVII

Gómez de Castro, A. 1569. De rebus gestis a Francisco Ximenio Cisnerio, archiepiscopo Toletano, libri octo. Compluti, apud Andream de Angulo.

Guadalupe, A. 1662. Historia de la Santa Provincia de los Ángeles, de la regular Observancia y Orden de nuestro seráfico Padre San Francisco. Madrid. Mateo Fernández.

Hefele, K. J. von. 1869. El Cardenal Jiménez de Cisneros y la Iglesia española a fines del S. XV y principios del XVI Barcelona, Imprenta del Diario de Barcelona.

Labajos Alonso, J. 2012: "Pedro de Osma y Fernando de Roa: significación histórica" en Flórez Miguel, C. /Hernández Marcos, M. / Albares Albares, R. (eds): La primera escuela de Salamanca (1406-1516). Salamanca. Eds. Universidad.

Lyell, J. P.R. 1917 Cardinal Ximenes statesman, ecclesiastic, soldier and man of letters. Londres. Grafton \&Co.

Meseguer Fernández, J. 1974. "Noticias sobre el cardenal Cisneros, sus padres y parientes" en Archivo Ibero Americano, 34: 287-97.

Navarro y Rodrigo, C. 1869. El cardenal Cisneros. Estudio biográfico Madrid, G. Estrada.

Porreño, B. 1918. Dos tratados históricos tocantes al cardenal Ximénez de Cisneros Madrid. Sociedad de Bibliófilos españoles.

Pou y Martí, J.M. 1920. “El Cardenal Cisneros, arcipreste de Uceda" en Archivo Ibero Americano 13: 413-17.

Quintanilla y Mendoza, P. 1653. Archetypo de virtudes, espejo de prelados, el venerable padre y siervo de Dios Fray Francisco Ximénez de Cisneros. Palermo, Nicolás Bua, impr.

Robles, E. 1604. Compendio de la vida y hazañas del Cardenal don Fray Francisco Ximénez de Cisneros; y del Oficio y Missa Muzárabe. Valladolid.

Rummel, E. 1999. Jiménez de Cisneros: On the Treshold of Spain's Golden Age. Tempe. Arizona Center for Medieval and Renaissance Studies.

Vallejo, J. 1913. Memorial de la vida de fray Francisco Jiménez de Cisneros. Torre, A. de la (ed.). Madrid. Imprenta Bailly-Bailliere.

Wadding, L. 1736. Annales minorum (2a ed. op. Josephi Ma Fonseca ab Ebora, 24 vols.) Roma, typis Rochi Bernabò. 